HNF-33756

Revision 0

\title{
Criticality Curves for Plutonium Hydraulic Fluid Mixtures
}

Prepared for the U.S. Department of Energy

Assistant Secretary for Environmental Management

Project Hanford Management Contractor for the

U.S. Departmenl of Energy under Contract DE-AC06-96RL13200

\section{FL018.}

P.O. Box 1000

Richland, Washington 


\section{Criticality Curves for Plutonium Hydraulic Fluid Mixtures}

Document Type: $\mathrm{CN}$

Program/Project: PFP

W. D. Wittekind

Fluor Hanford, Inc.

Date Published

August 2007

Prepared for the U.S. Department of Energy

Assistant Secretary for Environmental Management

Project Hanford Management Contractor for the

U.S. Department of Energy under Contract DE-AC06-96RL13200

\section{FLUOR.}

P.O. Box 1000

Richland, Washington

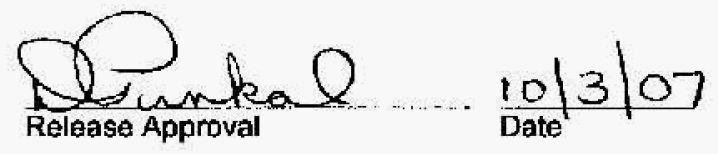

Release Approval
Release Stamp

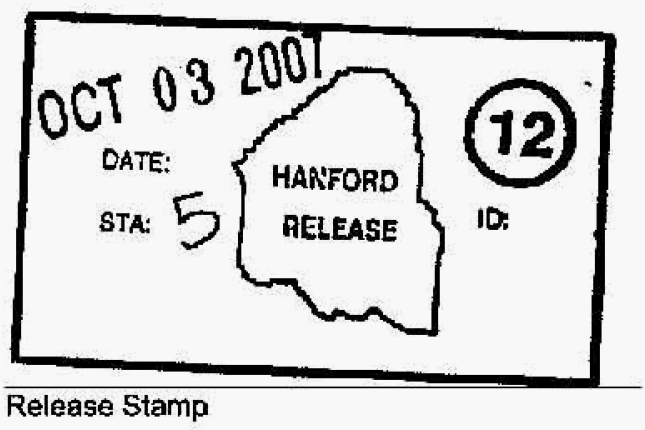

$$
\begin{aligned}
& \text { DOES NOT CONTAIN CLASSIFIED OR } \\
& \text { UNCLASSIFIED CONTROLLED } \\
& \text { NUCLEAR INFORMATION }
\end{aligned}
$$

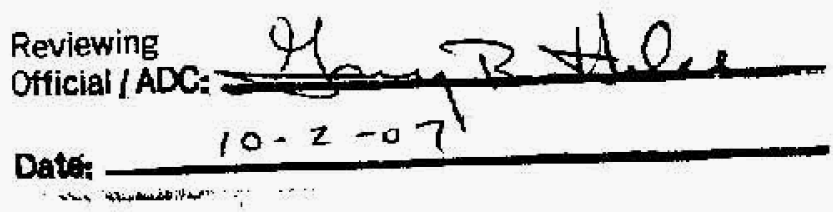

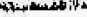

Approves for Pr.blic Release;

Further Dissemunatuon Undimited 
HNF-33756

Revision 0

TRADEMARK DISCLAMER

Reference herein to any specific commerclal product, process.

or service by trade nams, trademark, manufacturer, or

otherwise, does not necessarily constitute or imply lis

endorsement, recommendation, or favoring by the United

States Government or any agency thereof or its contractors or

subcontractors.

This report has been reproduced from the best available copy.

Pinted in the Unted States of America

Total Pages: $\quad 44$ 
HNF-33756, Rev. 0

\section{Calculation Cover Sheet and Revision Summary}

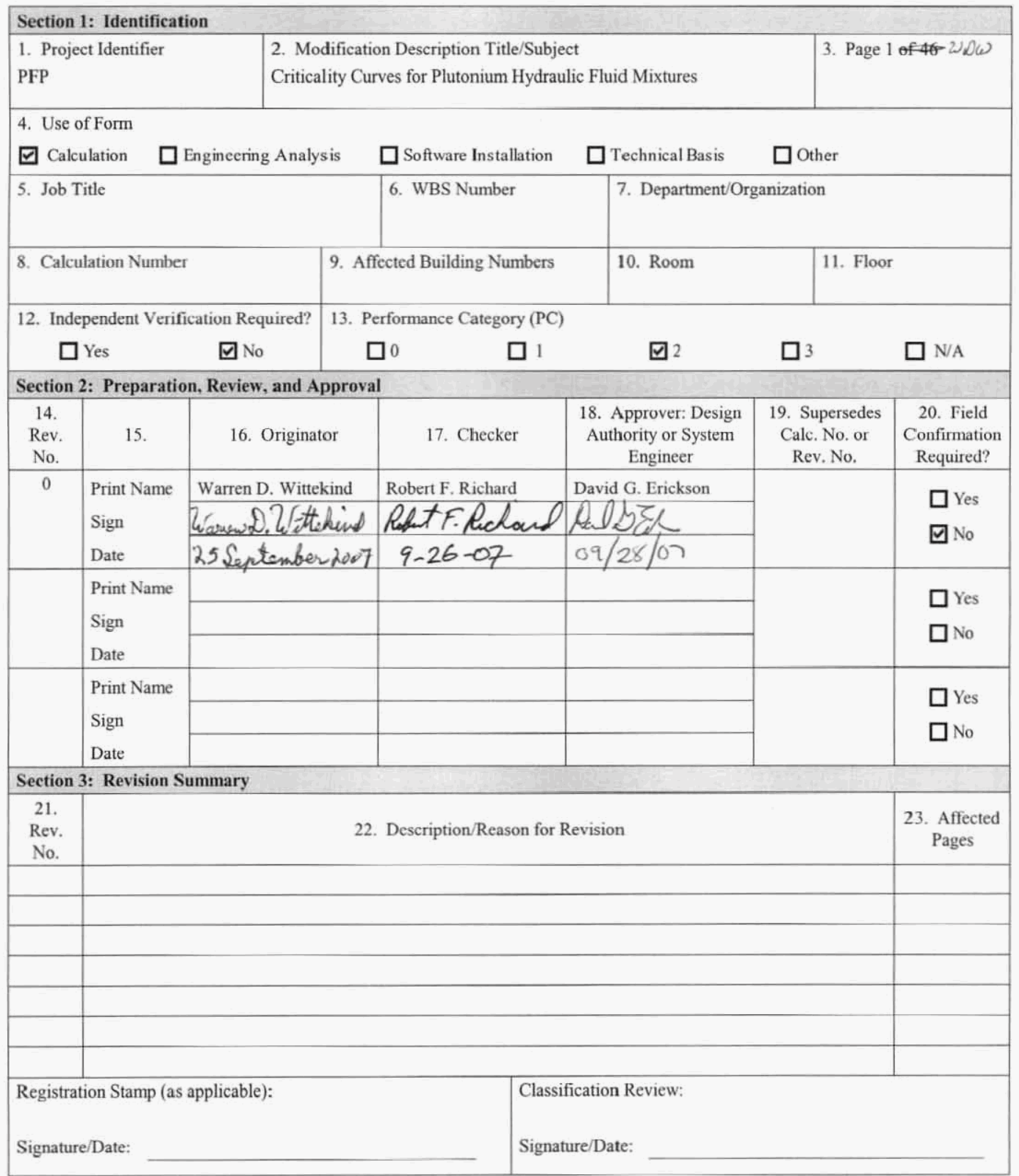


Criticality Curves for Plutonium Hydraulic Fluid Mixtures

HNF-33756, Rev. 0

\section{TABLE OF CONTENTS}

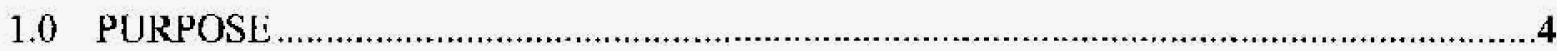

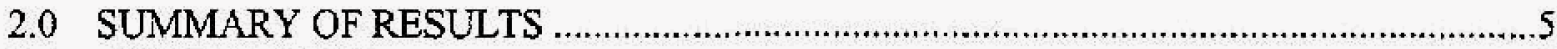

3.0 ASSUMPTIONS

4.0 SOFTWARE APPLICATIONS, DESCRIPTIONS, INSTALLATION \& CHECKOUT, AND STATEMENTS OF VALIDITY

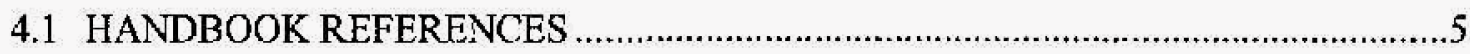

4.2 CRITICALITY SAFETY LIMIT

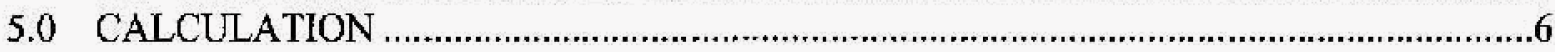

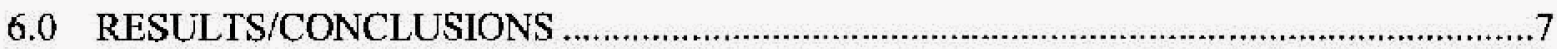

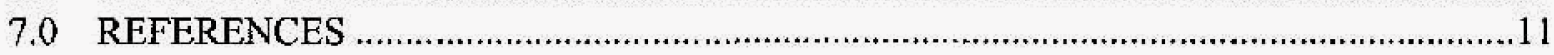

APPENDIX A - INDEPENDENT REVIEW COMMENTS AND CHECKLIST ................... A-1

APPENDIX B - MCNP COMPUTER CODE VAIIDATION.......................................

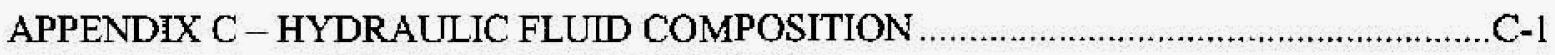

APPENDIX D - MCNP COMPUTER MODELING ......................................................... D-1

\section{LIST OF TABLES}

Table 6-1. Hydraulic Fluid Critical Curve Interpolated MCNP Calculated Results.................. 10

Table D-1. FYRQUEL ${ }^{\mathbb{B}} 220$ Best Available Composition................................................... D-3

Table D-2. Spreadsheet Calculation for Effective FYRQUEL ${ }^{1} 220$ Composition ................. [ -4

Table D-3. MCNP Composition and Dimensions for Pu-Hyclraulic Fluid $0.003 \mathrm{~g} / \mathrm{cm}^{3} \ldots \ldots \ldots . .$. D-6

Table D-4. MCNP Composition and Dimensions for Pu-Hydraulic Fluid $0.075 \mathrm{~g} / \mathrm{cm}^{3} \ldots \ldots \ldots \ldots$ D-7

Table D-5. MCNP Composition and Dimensions for Pu-Hydraulic Fluid $3.000 \mathrm{~g} / \mathrm{cm}^{3} \ldots \ldots \ldots . . . . .8$

\section{LIST OF FIGURES}

Figure 6-1. Critical Curves for Hydraulic Fluid............................................................... 8

Figure 6-2. MCNP Complete Curves for Hydraulic Fluid .................................................. 9

Figure B-1. Logic of Validation Procedure ......................................................................... B-3

Figure B-2. Implementation of Validation Procedure for Plutonium Metal Systems............... B-5

Figure B-3. Implementation of Validation Procedure for Moderated

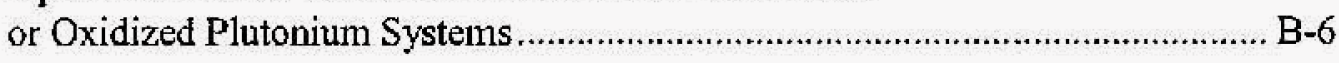


Criticality Curves for Plutonium Hydraulic Fluid Mixtures HNF-33756, Rev. 0

\section{List of Terms}

D\&D

$\mathrm{g} \mathrm{Pu}$

MCNP

PFP

PRF

RMA

SWB

decontamination and decommissioning

grams of plutonium

Monte Carlo N-Particle

Plutonium Finishing Plant

Plutonium Reclamation Facility

Remote Mechanical A-line

Standard Waste Box 


\section{Criticality Curves for Plutonium Hydraulic Fluid Mixtures \\ HNF-33756, Rcv. 0}

\subsection{PURPOSE}

This Calculation Note performs and documents MCNP criticality calculations for plutonium $\left(100 \%{ }^{239} \mathrm{Pu}\right)$ hydraulic fluid mixtures. Spherical gcomctry was used for these generalized criticality safety calculations and three geometries of neutron reflection are:

- bare,

- 1 inch of hydraulic fluid, or

- 12 inches of hydraulic fluid.

This document shows the critical volume and critical mass for various concentrations of plutonium in hydraulic fluid. Between 1 and 2 gallons of hydraulic fluid were discovered in the bottom of HA-23S. This HA-23S hydraulic fluid was reported by engineering to be Fyrquel $^{1} 220$. The hydraulic fluid in Glovebox HA-23S is Fyrquel ${ }^{2} 220$ which contains phosphorus. Critical spherical geometry in air is calculated with 0 in., 1 in., or 12 inches hydraulic fluid reflection.

This document fulfills the requirements of HNF-PRO-8259 PHMC Calculation Preparation and Issue (Including OCRWM) (FH 2007) regarding the documentation of calculations.

These plutonium hydraulic fluid mixture critical curves are intended for guidance and application to any operation where plutonium may be mixed with hydraulic fluid. The expected operation is to remove the hydraulic fluid, with an unknown amount of plutonium contamination in containers that may then be moved into a temporary waste container and then into a 55 gallon drum or into a Standard Waste Box (SWB). The hydraulic fluid or unknown oily substances may be encountered as various systems are disassembled during D\&D (e.g., the 26 in. vacuum system, the E-4 system, PRF Gallery Gloveboxes, transfer lines, remaining vesscls and piping in the RMA line, etc.) - this material will require safe handling, and the handbook capability must be expanded from water and nitric acid to Fyrquel ${ }^{\circ} 220$ and to other oily substances.

Glovebox HA-23S is rectangular in shape with approximate outside dimensions as follows: 189 inches long, 48 inches wide and 138 inches high. The bottom of the glovebox is raised on legs approximately 10 inches above the concrete floor. The glovebox is divided vertically into four levels, separated by expanded steel mesh floors (which may be removed during the course of the operation). Each level contains a conveyor that was previously used for storing fissionable material containers. The conveyors are approximately 34 inches apart vertically. Each conveyor is shaped like a racetrack; the straight-aways are approximately 123 inches long.

Fyrquel ${ }^{t}$ is a registered trademark of Supresta U.S. LLC LTL LIAB 


\section{Criticality Curves for Plutonium Hydraulic Fluid Mixtures}

HNF-33756, Rev. 0

Moveable 10-inch thick water walls surround one end and wo sides of the glovebox.

The water walls are normally full; however they may be empty or removed all together during the course of the operation. The south end of the glovebox abuts the HA-28 conveyor glovebox and contains a four level hydraulic pallet lift and personnel elevator access arca. Loading and unloading of pallets and equipment access is nomally performed on the second level, which has the HA- 28 access bay. Items and equipment are moved between levels on a hydraulic lift inside the glovebox.

Glovebox HA-23S was observed to have a collection of fluid in the bottom. The fluid was about six feet long, four feet wide and may have been between $1 / 8$ inch and $1 / 4$ inch thick at the deep end. Assuming wedge geometry, the volume calculated out to between one gallon and two gallons volume.

The plutonium was modeled as $100 w t \%{ }^{239} \mathrm{Pu}$. This composition will bound all reactor produced plutonium which has greater ${ }^{240} \mathrm{Pu}$ content than the ${ }^{241} \mathrm{Pu}$ content.

\subsection{SUMMARY OF RESULTS}

The critical mass of plutonium in hydranlic fluid is greater than the critical mass of plutonium in water. This means that criticality safety can conservatively use the plutonium water critical curves when setting criticality safety limits when dealing with hydraulic fluids.

\subsection{ASSUMPTIONS}

1. Assumes $100 \mathrm{wt} \%{ }^{239} \mathrm{Pu}$ in the plutonium.

2. Average hydraulic fluid mixlure of components is given in MSDS\# 014029 revision 3 (dated 04/24/2007)

3. Hydraulic fluid density is $1.17 \mathrm{~g} \mathrm{~cm}^{3}$, maximum from MSDS\# 014029 revision 3 (dated 04/24/2007).

4. Geometry is conservatively analyzed as a sphere.

5. Reflectors arc modeled as uniform shells of hydraulic fluid.

6. Plutonium is uniformly distributed throughout the hydraulic fluid.

\subsection{SOFTWARE APPLICATIONS, DESCRIPTIONS, INSTALLATION \& CHECKOUT, AND STATEMENTS OF VALIDITY}

\subsection{HANDBOOK REFERENCES}

Criticality handbooks, such as ARH-600 (Carter et al. 1968) with their figures are standard ways of communicating the criticality safety parameters of concem. Criticality handbooks have been used for a number of years and have been compared to other computer 


\section{Criticality Curves for Plutonium Hydraulic Fluid Mixtures \\ HNF-33756, Rev. 0}

computations by a number of criticality safety engineers in the course of validating or using the figures for criticality safety purposes.

\subsection{CRITICALITY SAFETY LIMIT}

The double contingency principle states that a nuclear process must have sufficient factors of safety in the operation so that at least two unlikely, independent, and concurrent changes in the process conditions are required before a criticality accident is possible. An "unlikely" change in conditions is defined as an upset having a probability of $\leq 0.01$ per year. Such an unlikely upset is also called a contingency.

A nuclear criticality requires a neutron multiplication factor $\left(\mathrm{k}_{\mathrm{eff}}\right)$ of unity, i.e., $\mathrm{k}_{\mathrm{eff}}=1.0$. Due to uncertainties, the $k_{\text {eff }}$ value for the point at which a criticality is considered "possible" includes a safety margin of $\Delta \mathrm{k}_{\mathrm{t} \text { ef }}=0.05$. It also must include the average bias in the computer code (MCNP 4C) as determined by comparison of calculations with experiments, the uncertainty in that ayerage bias, and the statistical uncertainty of the MCNP $4 \mathrm{C}$ calculations. The code validation summarized in Appendix B for MCNP $4 \mathrm{C}$ results in a $\mathrm{k}_{\text {eff }}$ limit of either 0.943 for a system of non-metal (including oxides) plutonium material, or 0.933 for plutonium metal systems. These values for the criticality safety limit are derived using 0.001 as the upper limit for the statistical uncertainty obtained in the MCNP calculations.

This analysis did not incorporate the 0.05 safety margin, or the MCNP code bias. When these results are used in a criticality safety application, care should be used to include the 0.05 safety margin and the MCNP code bias.

\subsection{CAlCulation}

Evaluation considers fissionable material in spheres with three different degrees of neutron reflection, bare, 1 inch hydraulic fluid, and 12 inches hydraulic fluid. The hydraulic fluid is Fyrque ${ }^{5 i} 220$, which is a butylated triphenyl phosphate mixture. $\mathrm{C}_{20222} \mathrm{H}_{21.35} \mathrm{O}_{4} \mathrm{P}$ was uscd for the average chemical composition at a density of $1.17 \mathrm{~g} / \mathrm{cm}^{3}$. The hydraulic flujd mixture information is more completely assembled in Appendix D, MCNP Computer Modeling. The plutonium was modeled as plutonium metal at $19.6 \mathrm{~g} / \mathrm{cm}^{3}$. Plutonium metal is considered to be conservative compared to the $\mathrm{PuO}_{2}$ that would realistically be expected to be found. The ${ }^{239} \mathrm{Pu}-$ $\mathrm{C}_{20.22} \mathrm{H}_{21.75} \mathrm{O}_{4} \mathrm{P}$ mixture was modeled with different plutonium densities with the $\mathrm{C}_{20.22} \mathrm{H}_{21.75} \mathrm{O}_{4} \mathrm{P}$ filling the void volume.

The analysis used the $\mathrm{C}_{20.22} \mathrm{H}_{21.75} \mathrm{O}_{4} \mathrm{P}$ formula. There were various plutonium densities between $19.60 \mathrm{~g} / \mathrm{cm}^{3}$ and $0.002 \mathrm{~g} \mathrm{Pu} / \mathrm{cm}^{3}$. A range of plutonium masses was calculated at all three neutron reflection conditions. The range of plutonium masses covered the subcritical and supercritical sides of the reactivity curve for all three neutron reflection conditions.

Handbook references did not include hydraulic fluid moderation or neutron reflection, and are being extended by MCNP calculations in this calculation note. 
Criticality Curves for Plutonium Hydraulic Fluid Mixtures

HNF-33756, Rev. 0

Plutonium composition is assumed to be $0 \mathrm{wt} \%{ }^{240} \mathrm{Pu}\left(100 \mathrm{wt} \%{ }^{239} \mathrm{Pu}\right)$. There is a very limited availability of low wt $\%{ }^{240} \mathrm{Pu}$ matcrial (Crowe and Szempruch 1994).

\subsection{RESULTS/CONCLUSIONS}

Critical curves of mass versus volume for plutonium in Fyrquel ${ }^{\sqrt{6}} 220$ hydraulic fluid are presented in Figure 6-1, Critical Curves for Hydraulic Fluid.

MCNP calculations showing the MCNP Plutonium mass and volume for cach Plutonium density in the sphere, or degree of moderation, are shown in Figure 6-2, MCNP Complete Curves for Hydraulic Fluid.

The MCNP calculated $\mathrm{k}_{\mathrm{eff}}$ are calculated at 10 different mass/volume sphere sizes, and then the $\mathrm{k}_{\mathrm{eff}}$ 's were used to interpolate to $\mathrm{k}_{\mathrm{eff}}=1.00$ for each plutonium density and for the three reflector models (bare, 1 inch hydraulic fluid, and 12 inches hydraulic fluid). These complete MCNP curves for hydraulic fluid are also tabulated in Table 6-1, Hydraulic Fluid Critical Curve Interpolated MCNP Calculated Results.

The MCNP calculated minimum critical mass for Plutonium mixed in hydraulic fluid is greater than the MCNP calculated minimum critical mass for Plutonium mixed in water. 
Criticality Curves for Plutonium Hydraulic Fluid Mixtures

HNF-33756, Rev. 0
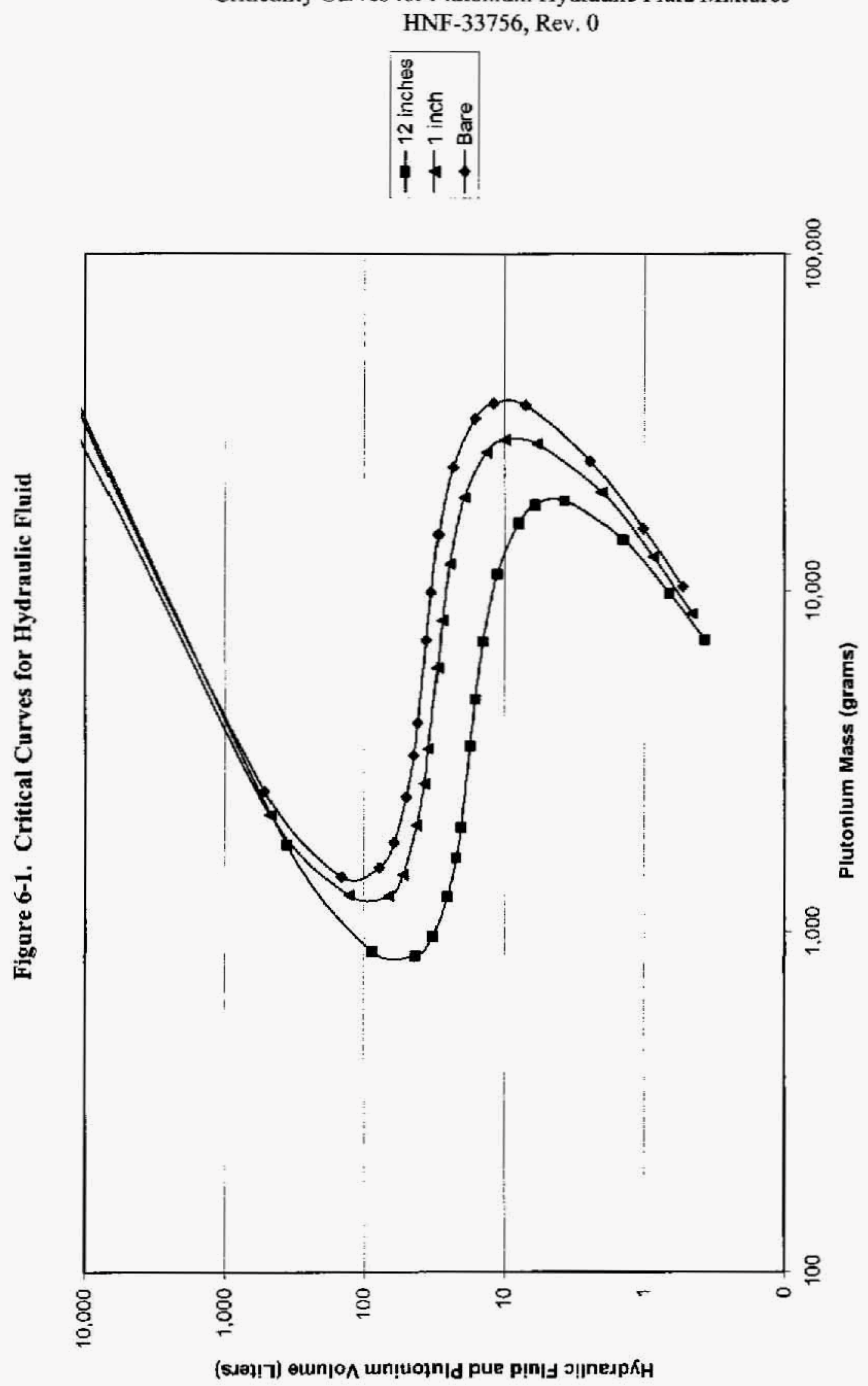
Criticality Curves for Plutonium Hydraulic Fluid Mixtures HNF-33756, Rev. 0

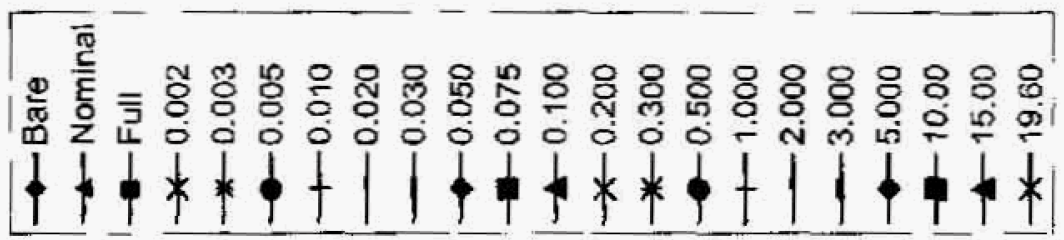

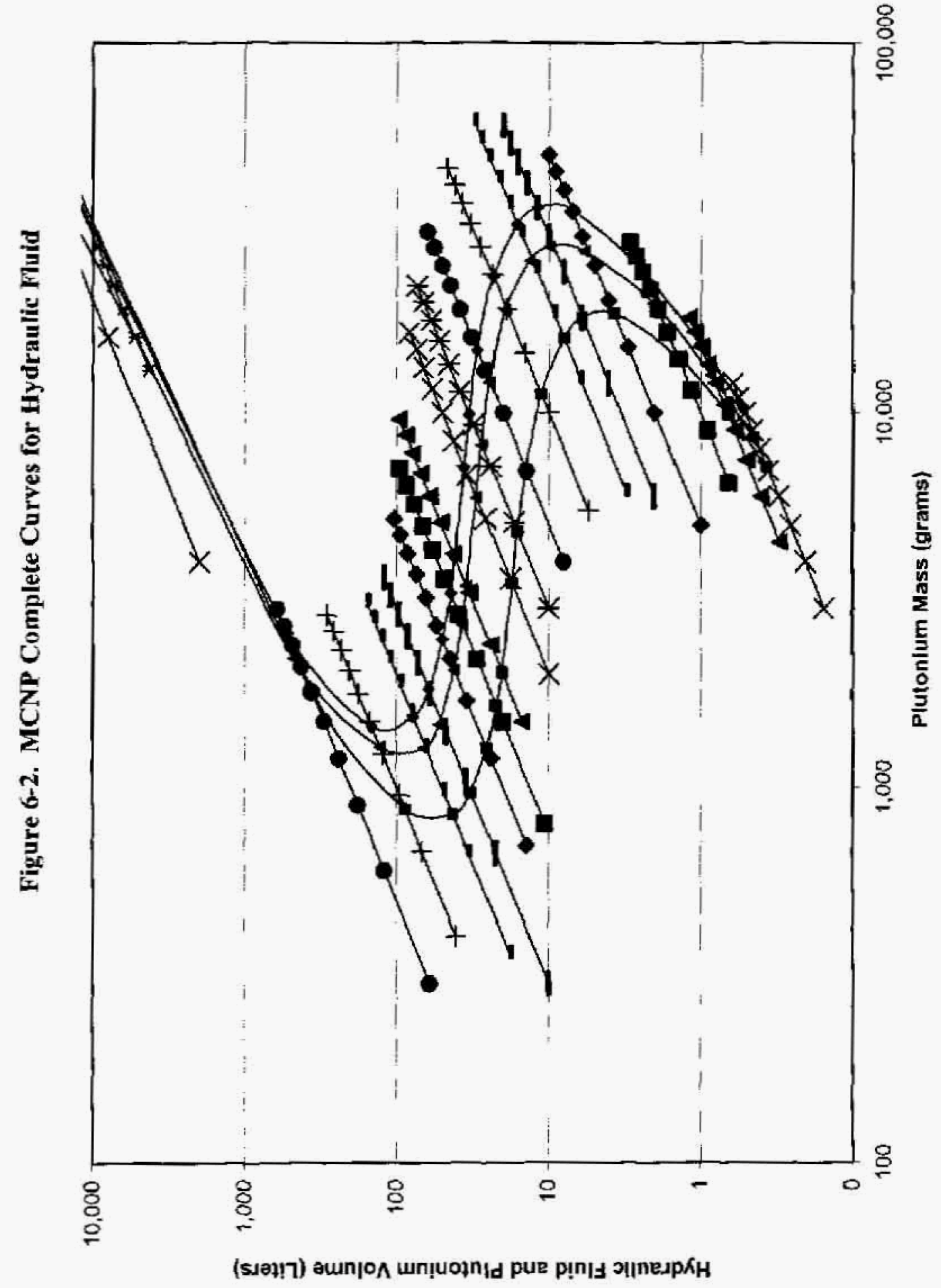




\section{Criticality Curves for Plutonium Hydraulic Fluid Mixtures}

HNF-33756, Rev. 0

Table 6-1. Hydraulic Fluid Critical Curve Interpolated MCNP Calculated Results

\begin{tabular}{|c|c|c|c|c|c|c|}
\hline \multicolumn{7}{|c|}{$\begin{array}{l}\text { Hydraulic Fluid Critical Curve Interpolated MCNP Calculated Results } \\
\text { Minimum MCNP Calculated } \mathrm{k}_{\mathrm{eff}}=1.0 \text { Masses with Voulumes are bold }\end{array}$} \\
\hline \multirow{2}{*}{$\begin{array}{c}\text { Pu density } \\
\text { g/Liter }\end{array}$} & \multicolumn{2}{|c|}{ Bare } & \multicolumn{2}{|c|}{1 Inch Reflection } & \multicolumn{2}{|c|}{12 Inches Reflection } \\
\hline & Volume (L) & Mass (g) & Volume (L) & Mass (g) & Volume (L) & Mass (g) \\
\hline 0.002 & $17,757,701.280$ & $35,515,402.6$ & $7,088,472.084$ & $13,252,304.4$ & $3,735,177.046$ & $, 470,354.1$ \\
\hline 0.003 & $14,362.584$ & $43,087.8$ & $20,743.707$ & $45,670.0$ & $24,069.555$ & $72,208.7$ \\
\hline 0.005 & 515.601 & $2,578.0$ & 473.841 & $2,204.9$ & 361.655 & $1,808.3$ \\
\hline 0.010 & 145.065 & $1,450.6$ & 128.057 & $1,281.4$ & 87.639 & 876.4 \\
\hline 0.020 & 77.272 & $1,545.4$ & 66.341 & $1,272.8$ & 42.529 & 850.6 \\
\hline 0.030 & 60.918 & $1,827.5$ & 52.189 & $1,472.0$ & 32.366 & 971.0 \\
\hline 0.050 & 49.592 & $2,479.6$ & 41.859 & $2,056.6$ & 25.423 & $1,271.2$ \\
\hline 0.075 & 43.890 & $3,291.7$ & 36.949 & $2,718.4$ & 22.052 & $1,653.9$ \\
\hline 0.100 & 40.927 & $4,092.7$ & 34.500 & $3,446.1$ & 20.355 & $2,035.5$ \\
\hline 0.200 & 35.721 & $7,144.2$ & 29.895 & $5,926.4$ & 17.562 & $3,512.3$ \\
\hline 0.300 & 33.026 & $9,907.9$ & 27.640 & $8,196.1$ & 16.071 & $4,821.3$ \\
\hline 0.500 & 29.324 & $14,661.8$ & 24.467 & $12,043.6$ & 14.211 & $7,105.7$ \\
\hline 1.000 & 23.310 & $23,310.0$ & 19.424 & $18,886.8$ & 11.244 & $11,244.1$ \\
\hline 2.000 & 16.234 & $32,467.5$ & 13.468 & $25,752.4$ & 7.943 & $15,886.0$ \\
\hline 3.000 & 11.996 & $35,989.5$ & 9.918 & $28,100.1$ & 5.998 & $17,992.5$ \\
\hline 5.000 & 7.113 & $35,566.1$ & 5.873 & $27,371.1$ & 3.699 & $18,496.3$ \\
\hline 10.000 & 2.428 & $24,281.9$ & 2.022 & $19,574.2$ & 1.418 & $14,184.3$ \\
\hline 15.000 & 1.017 & $15,249.0$ & 0.862 & $12,637.8$ & 0.660 & $9,894.8$ \\
\hline 19.600 & 0.526 & $10,301.9$ & 0.451 & $8,585.9$ & 0.367 & $7,184.3$ \\
\hline
\end{tabular}

Geometry is conservatively analyzed as a sphere. Mass was interpolated for $k_{\text {eff }}=1.00$ for the critical curves. Volume of the critical sphere is calculated from the mass (grams) divided by the concentration $\left(\mathrm{g} / \mathrm{cm}^{3}\right)$ and converted to Liters.

Density, concentration, and chemistry are all unrestricted because fissile material form is unrestricted.

Neutron moderation is unrestricted. Moderation, within the allowed maximum total volume for each Plutonium concentration, is used in the analysis.

There are no neutron absorbers credited for criticality safety in this analysis. The plutonium is mixcd with hydraulic fluid, the reflector is hydraulic fluid, outside the reflector is air and the end of the MCNP mathematical model. There were no neutron interaction items taken into account in the generation of these critical curves. 


\section{Criticality Curves for Plutonium Hydraulic Fluid Mixtures \\ HNF-33756, Rev. 0}

\subsection{REFERENCES}

Carter, R. D., G. R. Kjel, and G. R. Ridgeway, 1968, Criticality Handhook, ARH-600, Atlantic Hanford Company, Richland, Washington.

Crowe, R. D., and R. W. Szempruch, 1994, Technical Basis for Characterization of Plutonium for PFP Safety Analyses, WHC-SD.CP-TI-190, Rev. 0, Westinghouse Hanford Company, Richland, Washington.

FH, 2006, Criticality Safety Program, HNF-7098, Rev. 14, Fluor Hanford, Inc., Richland, Washington.

FH, 2007, PHMC Calculation Preparation and Issue (Including OCRWM), HNF-PRO-8259, Rev. 3, Fluor Hanford, Inc., Richland, Washington. 


\section{Criticality Curves for Plutonium Hydraulic Fluid Mixtures}

HNF-33756, Rev. 0

\section{APPENDIX A - INDEPENDENT REVIEW COMMENTS AND CHECKLIST}


Criticality Curves for Plutonium Hydraulic Fluid Mixtures
HNF-33756, Rcv, 0

Criticality Curves for Plutonium Hydraulic Fluid Mixtures
HNF-33756, Rcv. 0

This page is intentionally left blank.

(2) 


\section{Criticality Curves for Plutonium Hydraulic Fluid Mixtures \\ HNF-33756, Rev. 0}

\section{CIIECKLIST FOR TECHNICAL PEER REVIEW}

Document Reviewed - $\underline{\text { HNF-33756, Rev } 0}$

Title: Criticalily Curves for Plutonium Hydraulic Fluid Mixtures

Author(s): W. D. Wittekind

Date: August 2007

Scope of Review: Review of the document excluding the spreadsheets and MCNP.

\begin{tabular}{|c|c|c|}
\hline Yes & $\underline{\mathrm{No}^{*}}$ & $\underline{\mathrm{NA}}$ \\
\hline$\left[\begin{array}{lll}1 & 1\end{array}\right]$ & {$\left[\begin{array}{ll}1 & 1\end{array}\right.$} & {$\left[\begin{array}{ll}1 & ]\end{array}\right.$} \\
\hline$[\sim]$ & 11 & l I \\
\hline & [ ] & [M] \\
\hline $1 L$ & 11 & $\begin{array}{ll}1 & 1\end{array}$ \\
\hline & {$\left[\begin{array}{ll}{[} & 1\end{array}\right.$} & l I \\
\hline & {$\left[\begin{array}{ll}1 & 1\end{array}\right.$} & {$\left[\begin{array}{ll}1 & 1\end{array}\right.$} \\
\hline & 11 & {$\left[\begin{array}{ll}1 & ]\end{array}\right.$} \\
\hline 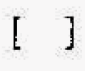 & {$\left[\begin{array}{ll}{[} & ]\end{array}\right.$} & [U] \\
\hline & {$\left[\begin{array}{ll}{[} & ]\end{array}\right.$} & [ ] \\
\hline 11 & {$\left[\begin{array}{ll} & ]\end{array}\right.$} & {$[\cup]$} \\
\hline [ & {$\left[\begin{array}{ll}{[} & ]\end{array}\right]$} & IV \\
\hline$\left[\begin{array}{ll}{[} & ]\end{array}\right.$ & $1 \mathrm{l}$ & [U] \\
\hline$\left[\begin{array}{ll}{[} & ]\end{array}\right.$ & {$\left[\begin{array}{ll}1 & ]\end{array}\right.$} & {$[\omega$} \\
\hline & {$\left[\begin{array}{ll} & ]\end{array}\right.$} & [L] \\
\hline & [ ] & {$\left[\begin{array}{ll}{[} & ]\end{array}\right.$} \\
\hline & {$\left[\begin{array}{ll}{[} & 1\end{array}\right.$} & {$\left[\begin{array}{ll}{[} & ]\end{array}\right.$} \\
\hline & [ ] & \\
\hline & & [U] \\
\hline [4] & & {$\left[\begin{array}{ll}1 & ]\end{array}\right.$} \\
\hline
\end{tabular}

Referenced analyses appropriate.

Problen completely defined and all potential configurations considered.

Accident scenarios developed in a clear and logical manner.

Necessary assumptions explicitly stated and supported.

Computer codes and data files documented.

Data used in calculations explicitly stated in document.

Data checked for consistency with original source information as applicable.

Mathematical derivations checked including dimensional consistency of results

Models appropriate and used within range of validity, or use outside range of established validity justified.

Hand calculations checked for errors. Spreadsheet results should be treated exactiy the same as hand calculations.

Software input correct and consistent with document reviewed.

Software output consistent with input and with results reported in dacument reviewed.

Limits/criteria/guidelines applied to analysis results are appropriate and referenced. I.imits/criteria/guidelines checked against references.

Salety margins consistent with good engineering practices.

Conclusions consistent with ana'ytical results and applicable limits.

Results and conclusions address all points required in the problem statement.

Format consistent with applicable guides or other standards.

Review calculations, comments, and/or notcs arc attached.

Document approved (for example, the reviewer affirms the technical aceuracy of the document).

\section{R.F. Richard RERelanel}

Technical Peer Reviewer (printed name and signature)

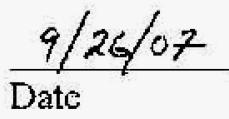

* All "no" responses must be explained below or on an additional sheet.

** Any calculations, comments, or notes generated as part of this review should be signed, dated and attached to this checklist. The material should be labeled and recorded in such a manner as to be understandable to a technically qualilied third pariy. 


\section{Criticality Curves for Plutonium Hydraulic Fluid Mixtures \\ HNF-33756, Rev. 0}

\section{CHECKLIST FOR TECHNICAL PEER REVIEW}

Document Revicwed - HNF-33756, Rev 0

Title: Criticality Curves for Plutonium Hydraulic Fluid Mixtures

Author(s): W. D. Wittekind

Date: August 2007

Scope of Review: Review of Spreadsheets and MCNP Only

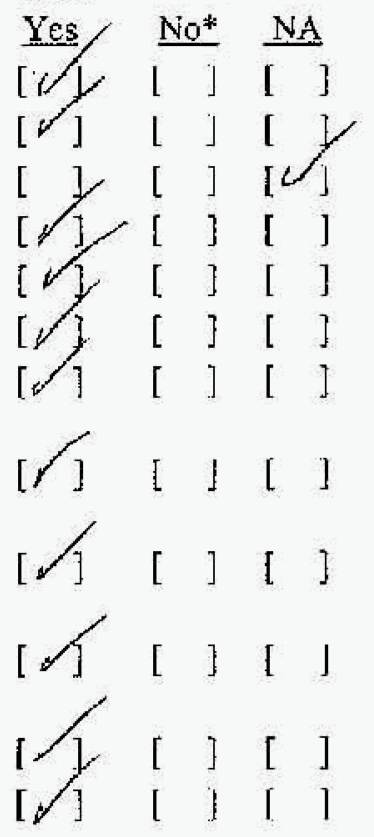

[ ] [ ] [ [ T

$\begin{array}{lllll}1 / 1 & 1 & ] & {[} & 1 \\ {[/]} & 1 & ] & 1 & 1 \\ {[1} & 1 & {[} & 1\end{array}$

$\begin{array}{llllll}{[/ 1} & {[} & ] & 1 & 1 \\ {[1 /} & {[} & ] & 1 & 1\end{array} * *$

Referenced analyses appropriate.

Problem completely defined and all potential configurations considered. Accident scenarios developed in a clear and logical manner.

Necessary assumptions explicitly stated and supported.

Computer codes and data files documented.

Data used in calculations explicitly stated in document.

Data checked for consistency with original source information as applicable.

Mathematical derivations checked including dimensional consistency of results

Models appropriate and uscd within range of validity, or use ontside range of established vaitity justified.

Hand calculations checked for errors. Spreadsheet results should be treated exactly the same as hand calculations.

Soltware input correct and consistent with document reviewed.

Software output consistent with input and with results reporled in document reviewed.

Limits/criteria/guidelines applied to analysis results are appropriate and referenced. Limits/criteria/guidelines checked against references.

Safety margurs consistent with good cnginecring practices.

Conclusions consistent with analytical results and applicable limits.

Rcsults and conclusions address all points required in the problem statement.

Format consistent with applicable guides or other standards.

* Review calculations, comments, and/or notes are attached.

Document approved (for example, the reviewer affirms the technica! accuracy of the document).

S. F. Kessler

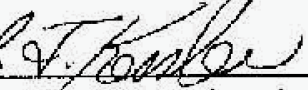

Technical Peer Reviewer (printed name and signature)

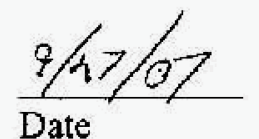

* All "no" rcsponses must be explained below or on an additional shect.

** Any calculations, comments, or notes generated as part of this review should be signed, dated and attached to this checklist. The material should be labeled and tecorded in such a manner as to be understandable to a technically qualified thiro party. 
Criticality Curves for Plutonium Hydraulic Fluid Mixtures HNF-33756, Rev. 0

APPENDLX B - MCNP COMPUTER CODE VALIDATION

B-1 
Criticality Curves for Plutonium Hydraulic Fluid Mixtures HNF-33756, Rev. 0

This page is intentionally left blank.

B-2 


\section{Criticality Curves for Plutonium Hydraulic Fluid Mixtures \\ HNF-33756, Rev. 0}

\section{MCNP4C COMPUTER CODE VALIDATION}

\section{B.I VAIIDATION PROCEDURE}

Validation of the MCNP4C computer code methods consisted of testing the code and its neutron cross section libraries against experiments of known critical configuration. These benchmark experiments have fissile isotopes in systems similar to thosc evaluated in this CSER. The computed and measured $\mathrm{k}_{\text {erf }}$ values for the benchmark configurations were compared to establish a bias that includes the uncertainty in the calculational methods. A bias-adjusted $k_{\text {eff }}$ for the benchmark systems was defined to include both the deviations of the calculated from the measured $\mathrm{k}_{\text {eff }}$ values, and experimental and calculation uncertainties along with a conservative allowance (a safety margin) for differences between the analyzed benchmarks and systems analyzed for this CSER. In addition, criticality safety criteria require that the bias-adjusted $k_{\text {eff }}$ for CSER analysis calculations not cxceed the established $k_{\text {eff }}$ safety limit at the $95 \%$ confidence level.

This method is illustrated in Figure B-1. Critical is defined as a $\mathrm{k}_{\text {efr }}$ of unity, adjusted by thc bias established from the comparison of calculations with benchmarks. The bias is combined with the safety margin of 0.05 (a safety limit that $k_{4, f f}$ must be less than or equal to 0.95 ) to compare with the calculated value and statistical uncertainty of the computer calculated $\mathrm{k}_{\text {eff }}$ values in this CSER analysis. The calculated target $\mathrm{k}_{\mathrm{r}}$ is established by adding the bias, 0.05 , and 1.645 times the one-sigma uncertainty of the calculated $k_{\text {eff }}$ for the particular CSER analysis and subtracting that value from 1.0. For the analyscs in this CSER, all of the computer statistical uncertainties were less than \pm 0.002 , so this value was used to set the $\mathrm{k}_{\text {efr }}$ limits, as described in Section B.2.

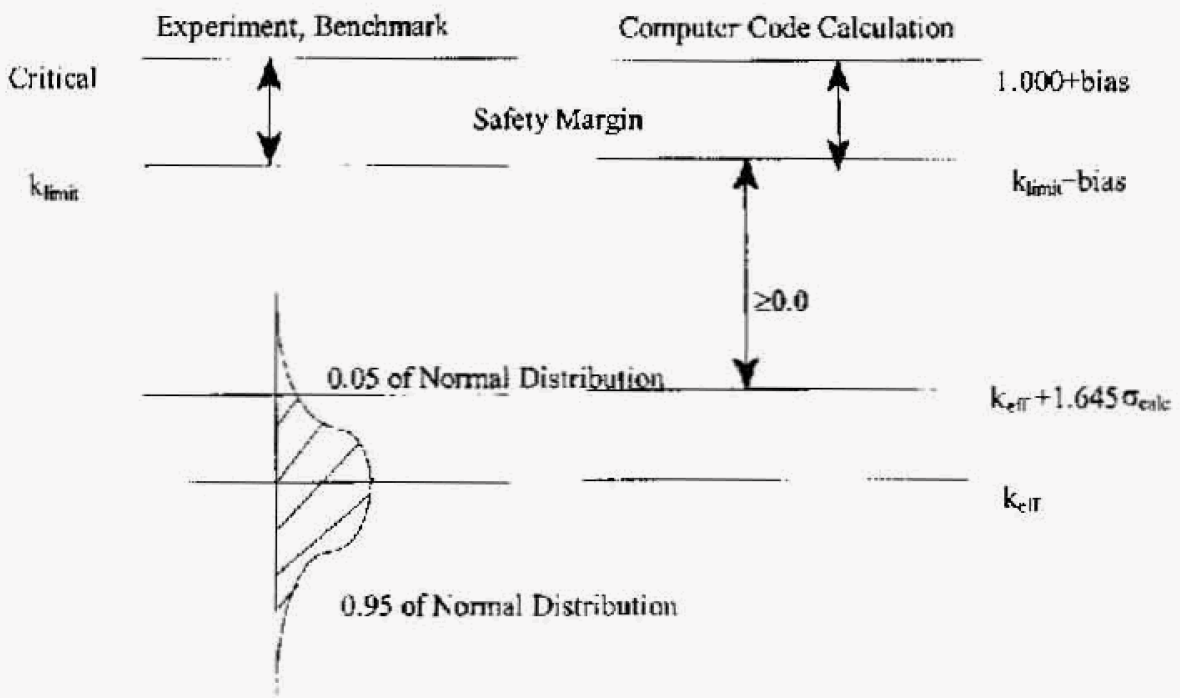

Figure B-1. Logic of Validation Procedure 


\section{Criticality Curves for Plutonium Hydraulic Fluid Mixtures \\ HNF-33756, Rev. 0}

\section{B.2 GENERIC VALIDATION FOR PLUTONIUM SYSTEMS}

A report, Engineering Computer Program Approval for Use, 620.290.MCNP4C, Rev. 1 (Lan 2003), presents the results of calculations to determine a generic bias for plutonium configurations, as encountered in the Plutonium Finishing Plant. One hundred and forty three benchmark experiments were calculated. There were different material types that were considered in the plutonium validation calculations:

- Plutonium metal,

- Plutonium oxide,

- Plutonium solutions,

- Plutonium solutions with cadmium (a neutron poison),

- Water and polystyrene moderators, and

- Water, Plexiglas, paraffin, polyethylene, and steel and concrete reflectors

The lower tolerance limit $\mathrm{b}_{\mathrm{L}}$ was calculated for the benchmark experiments such that there is $95 \%$ confidence that $95 \%$ of the benchmark calculated $\mathrm{k}_{\mathrm{c} f \mathrm{f}}$ 's is above that limit. This is expressed by the following formula:

$$
\mathbf{b}_{\mathrm{L}}=\mathbf{k}_{\mathrm{avg}}-\mathrm{K}_{\mathrm{b}} * \sigma_{\mathrm{avg}}
$$

where: $b_{\mathrm{L}} \quad-\quad$ lower tolerance limit for $95 \%$ confidence that $95 \%$ of the benchmark calculated $\mathrm{k}_{\mathrm{er}}$ 's is above this limit,

$\mathrm{k}_{\mathrm{avg}}=$ the average of the $\mathrm{k}_{\mathrm{efi}}$ 's calculated by MCNP4C,

$\mathrm{K}_{\mathrm{b}} \quad=$ a multiplier found from statistical tables for non-central $\mathrm{t}$-distribution, and depends on number of degrees of freedom, and

$\sigma_{\text {avg }} \quad=$ standard deviation of the MCNP ker's.

Bias is calculated by the following formula:

$$
\text { bias }=\mathrm{b}_{\mathrm{L}}-\mathrm{k}_{\mathrm{crit}}
$$

where:

$$
\begin{aligned}
& \mathbf{k}_{\text {crit }}-\text { the average of the } k_{\mathrm{efr}} \text { 's for the critical experiments; for the plutonium } \\
& \text { experiments } k_{\mathrm{cff}}=1.000 \text {. }
\end{aligned}
$$

The bias for the plutonium melal group was significantly different than for all other groups. For this reason, it was concluded that separate bias values for metal and non-metal groupings would be appropriate. The lower tolerance limit for the metal group ( 17 benchmark critical experiments) calculated to be 0.9884 . The lower tolerance limit for the non-metal group ( 126 benclimark critical experiments) calculated to be 0.9991 . These lower tolerance limits yielded the bias appropriate for each material category:

- Plutonium metal

- Plutonium non-metal bias is -0.0116 , bias is -0.0009 . 


\section{Criticality Curves for Plutonium Hydraulic Fluid Mixtures}

HNF-33756, Rev. 0

For conservatism, these calculated biases were recommended to be increased to:

- Plutoniurn metal recommended bias is -0.0150 ,

- Plutonium non-metal recommended bias is -0.0050 .

The safety critcria for futurc calculations on undctermined systems require that the bias adjusted $\mathrm{k}_{\text {eff }}$ does not exceed 0.95 at the $95 \%$ confidence level. This is expressed by the following formula:

$$
\mathrm{k}_{\mathrm{cft}}{ }^{*}=\mathrm{k}_{\mathrm{eft}}-\text { bias }+1.645 * \sigma_{\text {eale }} \leq \mathrm{k}_{\text {limit }}
$$

where: $\mathbf{k}_{\mathrm{efT}} \quad \mathrm{k}$ value given by MCNP4C calculation for system in question,

bias $=-0.015$ for Pu metal, and -0.005 for Pu non-metal systems,

1.645 = a constant number of standard deviations for 0.95 of the distribution for a one-sided standard normal distribution

$\sigma_{\text {calc }}=$ standard deviation given by MCNP4C calculation for system in question, and

$\mathrm{k}_{\text {limit }}=0.95$ for plutonium systems, generally.

$\mathrm{k}_{\text {limit }}$ is generally taken to be 0.95 for plutonium systems. is:

For a standard deviation ( $\sigma_{\text {calc }}$ ) of 0.001 or less, the $\mathrm{k}_{\text {eff }}$ value for plutonium metal systems

$$
\begin{gathered}
k_{\text {eff }}-(-0.015)+1.645 * 0.001 \leq 0.95 \text {, or } \\
k_{\text {cff }} \leq 0.95+(-0.015)-1.645 * 0.001=0.933 .
\end{gathered}
$$

On this basis, it is determined that the true $\mathbf{k}_{\text {eir }}$ of an analyzed configuration with plutonium will not exceed 0.95 with a $95 \%$ confidence level for plutonium metal systems if the calculated value ( $\mathrm{k}_{\text {effi, }}$ and $\sigma \leq 0.001$ ) is limited to a maximum value of $\mathbf{0 . 9 3 3}$, as illustrated in Figure B-2.

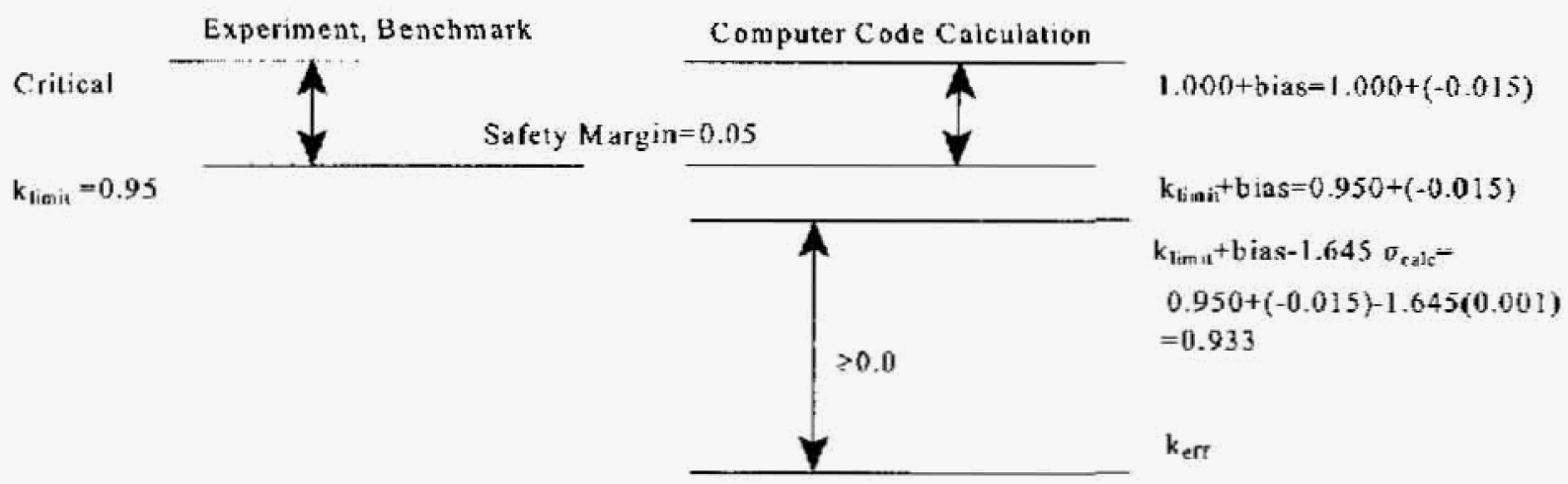

Figure B-2. Implementation of Validation Procedure for Plutonium Metal Systems 


\section{Criticality Curves for Plutonium Hydraulic Fluid Mixtures \\ HNF-33756, Rev. 0}

For a standard deviation ( $\sigma_{\text {calc }}$ ) of 0.001 or less, the $\mathrm{k}_{\text {eff }}$ value for non-metal systems is:

$$
\begin{gathered}
k_{\text {eff }}-(-0.005)+1.645 * 0.001 \leq 0.95, \text { or } \\
k_{\text {eff }} \leq 0.95+(-0.005)-1.645 * 0.001=0.943
\end{gathered}
$$

On this basis, it is determined that the true $\mathrm{k}_{\mathrm{eff}}$ of an analyzed configuration with plutonium will not exceed 0.95 with a $95 \%$ confidence level for plutonium non-metal systems if the calculated value ( $k_{\text {eff, }}$ and $\sigma \leq 0.001$ ) is limited to a maximum value of $\mathbf{0 . 9 4 3}$, as illustrated in Figure B-3.

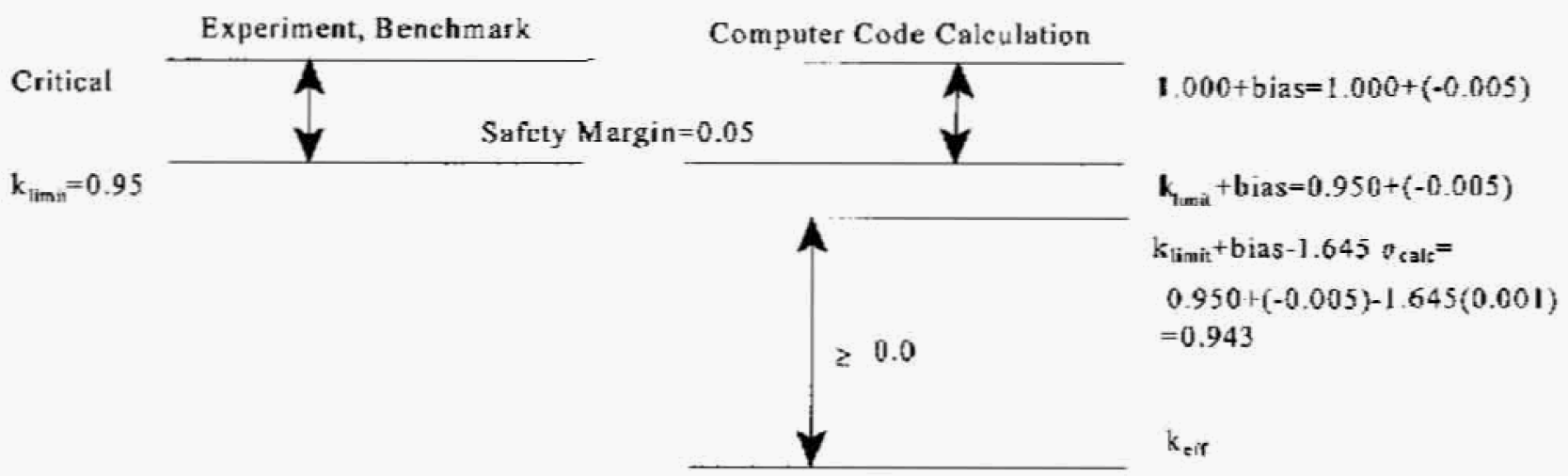

Figure B-3. Implementation of Validation Procedure for Moderated or Oxidized Plutonium Systems

\section{B.3 VALIDATION OF MCNP4C}

The validation of the MCNP4C code (Briesmeister 2001) on personal computers connectcd to the Fluor Local Area Network (FLAN) was documented in Lan 2003. These computers Dell@ Precision $\$ 360$ workstations operating under Microsoft( WindowsXP(B) Professional Version 5.1.2600

The essence of the validation was cross correlation of calculation results obtained with this code version and results of critical experiments.

\section{B.4 REFERENCES}

Bricsmeistcr, J. F., Editor, 2001, Monte Carlo N-Particle Transport Code System, CCC-701, Transport Methods Group, Los Alamos National Lab., June, 2001, Los Alamos, New Mexico.

Lan, J. S., 2003, Engineering Computer Program Approval for Use, 620.290.MCNP4C, Rev. 1, Fluor Federal Services, Inc., Richland, Washington.

Dell@ and Dell Precisione are registered trademarks of Dell Computer Corpora ration.

Microsofts and WindowsXPe are registered trademarks of the Microsoft Corporation. 
Criticality Curves for Plutonium Hydraulic Fluid Mixtures HNF-33756, Rev. 0

\section{APPENDIX C - HYDRAULIC FLUID COMPOSITION}


Criticality Curves for Plutonium Hydraulic Fluid Mixtures

HNF-33756, Rev. 0

This page is intentionally left blank. 


\section{Criticality Curves for Plutonium Hydraulic Fluid Mixtures \\ HNF-33756, Rev. 0}

Page $\geqq$ ot 1

\section{Wittekind, Warren D}

From: Larkin, Kaith A

Sent: Monday, May 14.2007 1:34 PM

To: Willekind, Warren D; Mcclellan, James A

Subject: HA-23S Hycraulic Fluid

Finally found where they drained the resevoir and replaced the fluid. It was performed per package 2Z-95-00088. The hydraulic fluid was replaced with Fyrquel 220. Chemical Name is: Butylated Triphenyl phosphate Mixtures.

Keith 
Criticality Curves for Plutonium Hydraulic Fluid Mixtures HNF-33756, Rcv. 0

This page is intentionally left blank. 
Criticality Curves for Plutonium Hydraulic Fluid Mixtures HNF-33756, Rev. 0

APPENDIX D - MCNP COMPUTER MODELING

D-1 
Criticality Curyes for Plulonium Hydraulic Fluid Mixtures HNF-33756, Rev. 0

This page is intentionally left blank. 


\section{Criticality Curves for Plutonium Hydraulic Fluid Mixturcs \\ HNF-33756, Rev. 0}

\section{D.0 Summary}

First, EXCEL ${ }^{\text {EXELS }}$ spreadsheet for plutonium-hydraulic fluid composition calculations was performed. Then this data was entered into MCNP input programs, and then data from MCNP output was interpolated to yield critical curves for three spherical geometries:

- Barc,

- 1 inch hydraulic fluid reflection, and

- 12 inches hydraulic fluid reflection.

\section{D.1 FYRQUEL 220 Composition}

The composition of Fyrqucl ${ }^{\oplus} 220$ is not cxact, but is known fairly well. Representative MSDSs were consulted for the best available composition, as shown in Table D-1, FYRQUEL 220 Best Available Composition.

Table D-1. FYRQUEI 220 Best Available Composition

\begin{tabular}{|c|c|c|}
\hline \multicolumn{3}{|c|}{ FYRQUEL ${ }^{2} 220$ Best Available Composition } \\
\hline CAS \# & Description & Composition \\
\hline \multicolumn{3}{|c|}{ MSDS\# 014029 revision 3 (dated04/24/2007) Given Composition For FYRQUEL 220} \\
\hline $65632-41-7$ & Bis(t-butylphenyl) phenyl phosphate & $30-35 \%$ \\
\hline $56803-37-3$ & t-Butylphenyl diphenyl phosphate & $30-35 \%$ \\
\hline $115-86-6$ & Triphenyl phosphate & $15-25 \%$ \\
\hline \multirow[t]{2}{*}{$78-33-1$} & Tri(t-butylphenyl) phosphate & $10-15 \%$ \\
\hline & Specific gravity $=1.13 \quad 1.17 \mathrm{~g} / \mathrm{cm}^{3}$ at $20^{\circ} \mathrm{C}\left(68^{\circ} \mathrm{F}\right)$ & \\
\hline \multicolumn{3}{|c|}{ MSDS\# 16-084447 (dated 10/29/1997) Given Composition For FYRQUEL ${ }_{220}$} \\
\hline $115-86-6$ & Triphenyl phosphate & $15-25 \%$ \\
\hline \multirow[t]{2}{*}{ Mixture } & Butylated triphenyl phosphate mixture & $75-85 \%$ \\
\hline & Specific gravity not determined & \\
\hline \multicolumn{3}{|c|}{ MSDS\# CGLTW (dated 12/08/1999) Given Composition For FYRQUEL ${ }^{\text {2 }} 220$} \\
\hline $115-86-6$ & Triphenyl phosphate & $15-25 \%$ \\
\hline \multirow[t]{2}{*}{ Mixture } & Butylated triphenyl phosphate mixture & $75-85 \%$ \\
\hline & Spccific gravity not determined & \\
\hline \multicolumn{3}{|c|}{ MSDS\# 184048 (dated 10/09/1998) Given Composition For FYRQUEL ${ }^{9} 20$} \\
\hline $115-86-6$ & Triphenyl phosphate & $15-25 \%$ \\
\hline \multirow[t]{2}{*}{56803373} & Phosphoric Acid, (1,1-Dimethylethyl)phenyl diphenyl ester & $75-85 \%$ \\
\hline & Specific gravity $=1 \mathrm{~g} / \mathrm{cm}^{3}$ & \\
\hline
\end{tabular}

MSDS \# 014029 had enough information that an average FRYQUEL $\otimes 220$ composition could be calculated. This was performed as shown in Table D-2, Spreadsheet Calculation for Effective FYRQUEL $L^{\oplus} 220$ Composition. Density of $1.17 \mathrm{~g}^{\mathrm{cm}} \mathrm{cm}^{3}$ was used in these EXCEL + MCNP calculations.

EXCELO is a registered trademark of Microsoft Corporation. 
Criticality Curves for Plutonium Hydraulic Fluid Mixtures

HNF-33756, Rev. 0

Table D-2. Spreadsheet Calculation for Effective FYRQUEL ${ }^{\otimes} 20$ Composition

\begin{tabular}{|l|r|r|r|r|r|r|r||}
\hline \multicolumn{7}{|c||}{ Spreadsheet Calculation for Effective FYRQUEL } \\
\hline & CAS \# = & $65652-41-7$ & $56803-37-3$ & $115-86-6$ & $78-33-1$ & & \\
\hline & & & & & & & \\
\hline Carbon & $\mathrm{C}$ & 16 & 22 & 18 & 30 & & \\
\hline Hydrogen & $\mathrm{H}$ & 18 & 23 & 15 & 39 & & \\
\hline Oxygen & 0 & 4 & 4 & 4 & 4 & & \\
\hline Phosphorus & $\mathrm{P}$ & 1 & 1 & 1 & 1 & & \\
\hline & & & & & & & \\
\hline & Minimum & 30 & 30 & 15 & 10 & 85 & Minimum \\
\hline & Maximum & 35 & 35 & 25 & 15 & 110 & Maximum \\
\hline & Spread & 5 & 5 & 10 & 5 & 25 & Spread \\
\hline & & & & & & & \\
\hline & 0.6 & 33 & 33 & 21 & 13 & 100 & Normalized \\
\hline & & & & & & & \\
\hline & $\mathrm{C}$ & 5.28 & 7.26 & 3.78 & 3.9 & 20.22 & \\
\hline & $\mathrm{H}$ & 5.94 & 7.59 & 3.15 & 5.07 & 21.75 & \\
\hline & $\mathrm{O}$ & 1.32 & 1.32 & 0.84 & 0.52 & 4 & \\
\hline & $\mathrm{P}$ & 0.33 & 0.33 & 0.21 & 0.13 & 1 & \\
\hline
\end{tabular}

\section{D.2 Introduction}

The goal was to produce a critical curve for plutonium $\left(0 \mathrm{wt} \%{ }^{240} \mathrm{Pu}\right)$ for spheres that had:

- No reflection (Bare),

- 1 inch hydraulic fluid reflection (nominal reflection), and

- 12 inches hydraulic fluid reflection (full reflection).

The hydraulic was identified as Fyrquel ${ }^{(8)} 220$. The MSDS selected gave $\mathrm{C}_{20.22} \mathrm{H}_{21.75} \mathrm{O}_{4} \mathrm{P}$ as the effective molecular formula.

\section{D.3 EXCEL Spreadsheets for Plutonium and Hydraulic Flu id Composition}

EXCEL spreadsheets reproduced as Table D-3, MCNP Composition and Dimensions for $P u$-Hydraulic Fluid $0.003 \mathrm{~g} / \mathrm{cm}^{3}$, Table D-4, MCNP Composition and Dimensions for PuIydraulic Fluid $0.075 \mathrm{~g} / \mathrm{cm}^{3}$, and Table D-5, MCNP Composition and Dimensions for PuHydraulic Fluid $3.000 \mathrm{~g} / \mathrm{cm}^{3}$.

The EXCEL spreadsheets calculated the Pu-hydraulic fluid mixture composition for plutonium densities from 19,600 grams per Liter down to 2 grams per Liter to cover the entire range of plutonium fluid mixtures. This was intended to produce a curve similar to Figure III.A.9(100)-4, Critical Sphere Volume v. Critical Sphere Mass Plutonium- $\mathrm{H}_{2} \mathrm{O}-0$ wt\% ${ }^{240} \mathrm{Pu}$, from the ARH- 600 criticality handbook 


\section{Criticality Curves for Plutonjum Hydraulic Fluid Mixtures}

HNF-33756, Rev. 0

Ten MCNP cases were executed for each Pu density in the (1) Bare, (2) 1" fluid, and (3) 12 " fluid reflection configurations. Then interpolation was performed to locate $\mathrm{k}_{\mathrm{erf}}=1.000$ from the data. This gave a spherical mass, and because the Pu density was fixed, the plutonium volume for that Pu density. A "Bare" critical curve was produced by connecting all the Pu densities for the bare critical spherical configuration.

\section{D.4 MCNP Input Files}

There are three MCNP input files listed in this appendix at different plutonium concentrations.

\section{D.5 Lagrangian Interpolation for Critical Points}

The calculated values of $k_{\mathrm{tft}}$ from the MCNP calculations were used as base points for Lagrangian polynomial interpolation. Each plutonium conccntration was MCNP computed for ten different masses. Then MCNP calculated the $k_{\text {eff }}$ for each mass at this specific plutonium concentration. It is desired to know the mass where $\mathrm{k}_{\mathrm{eff}}=1.000$. The $\mathrm{k}_{\mathrm{efr}}$ is the independent variable, $\mathrm{x}_{\mathrm{i}}$, while the mass is dependent variable, $\mathrm{F}\left(\mathrm{x}_{\mathrm{i}}\right)$. The 3-point Lagrangian polynomial was then used to determine $k_{\text {eff }}=1.000$. There is some curvature in the mass versus $k_{\text {eff }}$ curve, so quadratic interpolation was used instead of linear (two point) interpolation. These calculations were performed in EXCEL using the MCNP4C $k_{\text {eff }}$ values to high precision.

Given the Lagrangian interpolation polynomial $\left(F(x)=\right.$ mass, and $\left.x=k_{e f f}\right)$ and $x=1.000$ :

$$
F(x)=\sum_{i=1}^{3} \prod_{\substack{j=1 \\ j \rightarrow i}}^{3} \frac{\left(x-x_{j}\right)}{\left(x_{i}-x_{j}\right)} F\left(x_{i}\right)
$$

$\mathrm{Or}$, in explicit form, where $\mathrm{x}=1$ has been substituted, this interpolation would appear as in (2).

$$
F(x)=\frac{\left(1-x_{i-1}\right)\left(1-x_{i-2}\right)}{\left(x_{i}-x_{i+1}\right)\left(x_{i}-x_{i+2}\right)} F\left(x_{i}\right)+\frac{\left(1-x_{i}\right)\left(1-x_{i+2}\right)}{\left(x_{i+1}-x_{i}\right)\left(x_{i+1}-x_{i+2}\right)} F\left(x_{i+1}\right)+\frac{\left(1-x_{i}\right)\left(1-x_{i+1}\right)}{\left(x_{i+2}-x_{i}\right)\left(x_{i+2}-x_{i+1}\right)} F\left(x_{i+2}\right)
$$

The most appropriate interpolation is where at least one point is on each sidc of the $\mathrm{k}_{\mathrm{eff}}=1$ desircd value. Finally, after the interpolated mass at $k_{\text {err }}=1$ has been determined, then the plutonium concentration is divided into the mass to determine the volume of this critical configuration.

The critical masses along with the critical volumes are then plotted as points on a critical curve of mass versus volume for each of the three geometries. 
Table D-3. MCNP Composition and Dimensions for Pu-Hydraulic Fluid $0.003 \mathrm{~g} / \mathrm{cm}^{3}$

Input is $\mathrm{Pu}(\mathrm{g} / \mathrm{L}), \mathrm{Pu}$ Mass (g) (10 evenly spaced), Output is MCNP composition, sphere dimensions

\begin{tabular}{|c|c|c|c|c|c|c|c|c|c|c|c|c|}
\hline \multicolumn{13}{|c|}{ MCNP Composition and Dimensions for Plutonium-Hydraulic Fluid $0.003 \mathrm{~g} / \mathrm{cm}^{3}$} \\
\hline 239.0522 & $P_{U}-\mathrm{C} 20.22 \mathrm{H} 21$ & $504 \mathrm{P}$ & & & & & & & & & & \\
\hline 240.0540 & $240 \mathrm{Pu} / \mathrm{Pu} w \%$ & 0 & & 0 & 0 & $\mathrm{a}$ & 0 & a & 0 & 0 & & INPUT \\
\hline $\mathrm{H}$ & Mass $\mathrm{Pu}$ & 13,000 & 16,000 & 19.000 & 22,000 & 25,000 & 28,000 & 31,000 & 34,000 & 37,000 & 40,000 & INPSUT \\
\hline 1.00797 & Pu $\left(\mathrm{g}^{\mathrm{cm}} \mathrm{cm}^{\wedge} 3\right)$ & 0.003 & 0,003 & 0.003 & 0.003 & 0.003 & 0.003 & 0.003 & 0.003 & 0.003 & 0.003 & IINPITT \\
\hline C & Pu (grams $/ L$ ) & 3 & 3 & 3 & 3 & -3 & 3 & 3 & 3 & 3 & 3 & \\
\hline 12.0111 & & & & & & & & & & & & \\
\hline 0 & $\mathrm{Vol} P \mathrm{Pu}\left(\mathrm{cm}^{\star} 3\right)$ & 663.26531 & 816.32653 & 969.38776 & 1122.449 & 1275.5102 & 1428.5714 & 1581,6327 & 1734.6939 & 1887.7551 & 2040.8163 & \\
\hline 15.9994 & Vol Hyd.Oil & 4332670.1 & 5332517 & 6332363.9 & 7332210.9 & 8332057.8 & 9331904.8 & 10331752 & 11331599 & 12331446 & 13331293 & \\
\hline $\mathrm{P}$ & Vol. Total & 4333333.3 & 5333333.3 & 6333333.3 & 7333333.3 & 8333333.3 & 9333333.3 & 10333333 & 11333333 & 12333333 & 13333333 & \\
\hline 30.97376 & & & & & & & & & & & & \\
\hline & Mass Pu & 13000 & 16000 & 19000 & 22000 & 25000 & 28000 & 31000 & 34000 & 37000 & 40000 & \\
\hline 21.75 & Mass Hyd. Oil & 5069224 & 6239045 & 7408066 & 8578687 & 9746508 & 10919329 & 12088149 & 13257970 & 14427791 & 15597612 & \\
\hline 20.22 & \begin{tabular}{|l} 
Mass Total \\
\end{tabular} & 5082224 & 6255045 & 7427866 & 8600697 & 9773508 & 10946329 & 12119149 & 13291970 & 14464791 & 15637612 & \\
\hline 4 & & & & & & & & & & & & \\
\hline & $\mathrm{H}: \mathrm{Pu}$ & 5635.58 & 5635.58 & 5635.58 & 5635.58 & 5635.58 & 5635.58 & 5635.59 & 5635.58 & 5635.58 & 5635.58 & OUTPUT \\
\hline & & & & & & & & & & & & \\
\hline 19.6 & Density & 1,172821 & 1.172821 & $1 . \overline{172821}$ & 1.172821 & 1.172821 & 1.172821 & 1.172821 & 1.172821 & 1.172821 & 1.172821 & OUTPUT \\
\hline 1.17 & Density Pu & 0.003000 & 0.003000 & 0.003000 & 0.003000 & 0.003000 & 0.003000 & 0.003000 & 0.003000 & 0.003000 & 0.003000 & \\
\hline$w+\%$ & & & & & -0.060783 & -0.060783 & -0.060783 & & & -0.060783 & & OUTPUT \\
\hline$\frac{\omega q}{w i \% c}$ & $\frac{1001.50 \mathrm{c}}{6000.50 \mathrm{c}}$ & $\frac{-0.673348}{-0.678}$ & - & -0.673348 & -0.673348 & -0.673348 & -0.673348 & -0.673348 & $-0,673348$ & -0.673348 & - & $\begin{array}{l}\text { OUTPUT } \\
\text { OUTP }\end{array}$ \\
\hline$w+\% O$ & $8016.50 \mathrm{c}$ & -0.177435 & -0.177435 & -0.177435 & -0.177435 & -0.177435 & -0.777435 & -0.177435 & -0.177435 & -0.177435 & -0.177435 & DUTPUT \\
\hline$w t \% \mathrm{P}$ & $15031.50 \mathrm{c}$ & -0.085876 & -0.085876 & -0.085976 & -0.085876 & -0.085876 & -0.085876 & -0.085876 & -0.085876 & -0.005876 & -0.085676 & OUTPUT \\
\hline$w+\%{ }^{2}{ }^{238} \mathrm{Pu}$ & $94239.55 \mathrm{c}$ & -0.002558 & -0.002558 & -0.002568 & -0.002558 & -0.002658 & -0.002558 & 0.002558 & -0.002550 & -0.002558 & -0.002558 & OUTPUT \\
\hline$w 6 \%{ }^{200} \mathrm{Pu}$ & $94240.50 \mathrm{c}$ & 0.000000 & 0.000000 & 0.000000 & 0000000 & 0.000000 & 0000000 & 0.000000 & 0.000000 & 0.000000 & 0.000000 & OUTPUT \\
\hline & Sumt & -1 & -1 & -1 & -1 & -1 & -1 & -1 & -1 & -1 & -1 & \\
\hline & Sphere $(\mathrm{cm})$ & 101.137255 & 108.385214 & 114.775161 & 120.523275 & 125.769900 & 130.611893 & 135.119266 & 139.344453 & 143.327861 & 147.101367 & OUTPUT \\
\hline & Sph. 1"Ref $\mathrm{cm}$ & 103.677255 & 110.925214 & 117.315161 & 123.063279 & 128.309900 & 133.151893 & 137.659260 & 141.884453 & 145.867861 & 149.641367 & OUTPUT \\
\hline & Sph. 12'Ref cm, & 131.617255 & 138.865214 & 145.255161 & 151.003279 & 156.249900 & 161.091893 & 165.599266 & 169.824453 & 173.807961 & 177.581367 & OUTPUT \\
\hline & & & 0000 & -1 & & & & & & & & \\
\hline$w \% H$ & $\frac{1001.50 c}{6000.50 \mathrm{c}}$ & -0.060939 & $\frac{-D \text { - }}{-0675075}$ & $\frac{-0.000909}{-0.675075}$ & $\frac{-0,060939}{-0,675075}$ & $\frac{-0,060939}{-0.675075}$ & $\begin{array}{l}-0.0609399 \\
-0.075755 \\
\end{array}$ & $\frac{-0.060309}{-0.675075}$ & -0.060939 & $-0,060939$ & -0.060939 & OUTPUT \\
\hline 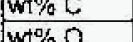 & $\frac{6000.50 \mathrm{c}}{\mathrm{g} 016.50 \mathrm{c}}$ & -0.177890 & & -0.177890 & -0.177890 & -0.177990 & -0.177890 & $=-0.177890$ & 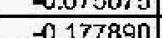 & -0.0775800 & $\frac{-0.675075}{-0.177900}$ & $\begin{array}{l}\text { OUIPUT } \\
\text { OTITIT }\end{array}$ \\
\hline $\mathrm{wt} \% \mathrm{~F}$ & $15031.50 \mathrm{C}$ & -0.086096 & -0.066056 & -0.086096 & .0 .086096 & -0.096096 & -0.086096 & $-0,086096$ & -0.066096 & -0.086096 & -0.085096 & OUTPUT \\
\hline & Sum & -1 & \begin{tabular}{|c|}
-1 \\
\end{tabular} & -1 & -1 & -1 & $\begin{array}{r}-1 \\
-1\end{array}$ & -1 & -1 & -1 & -1 & \\
\hline
\end{tabular}


Table D-4. MCNP Composition and Dimensions for Pu-Hydraulic Fluid $0.075 \mathrm{~g} / \mathrm{cm}^{3}$

Input is $\mathrm{Pu}(\mathrm{g} / \mathrm{L}), \mathrm{Pu}$ Mass (g) (10 evenly spaced), Output is MCNP composition, sphere dimensions MCNP Composition and Dimensions for Plutonium-Hydraulic Fluid $0.075 \mathrm{~g} / \mathrm{cm}^{3}$

\begin{tabular}{|c|c|c|c|c|c|c|c|c|c|c|c|c|}
\hline \multicolumn{13}{|c|}{ MCNP Composition and Dimensions for Plutonium-Hydraulic Fluid $0.075 \mathrm{~g} / \mathrm{cm}^{3}$} \\
\hline 239.0522 & $\mathrm{Pu}-\mathrm{C} 20.22 \mathrm{H} 21$ & $24 \mathrm{P}$ & & & & & & & & & & \\
\hline 240.0540 & ${ }^{210}$ PuPu wt\% & 0 & 0 & 0 & 0 & 0 & 0 & 0 & 0 & 0 & 0 & IINPUT \\
\hline $\mathrm{H}$ & Mass Pu & 800 & 1,500 & 2,200 & 2,900 & 3,600 & 4,300 & 5,000 & 5,700 & 6,400 & 7,100 & INPUT \\
\hline 1.00797 & Pu $\left(\mathrm{g} \mathrm{Pu} / \mathrm{cm}^{\wedge} 3\right)$ & 0.075 & 0.075 & 0.075 & 0.075 & 0.075 & 0075 & 0.075 & 0.075 & 0.075 & 0.075 & INPUT \\
\hline C & Pu (grams/L) & 75 & 75 & 75 & 75 & 75 & 75 & 75 & 75 & 75 & 75 & \\
\hline 12.0111 & & & & & & & & & & & & \\
\hline 0 & Vol Pu $\left(\mathrm{cm}^{\wedge} 3\right)$ & 40.81633 & 76.53061 & 112.2449 & 147.9592 & 183.6735 & 219.3878 & 255.102 & 290.8163 & 326.5306 & 362.2449 & \\
\hline 15.9994 & Vol Hyd. Oil & 10625.85 & 19923.47 & 29221.09 & 38518.71 & 47816.33 & 57113.95 & 66411.56 & 75709.18 & 85006.8 & 94304.42 & \\
\hline $\bar{P}$ & Vol. Total & 10666.67 & 20000 & 29333.33 & 38666.67 & 48000 & 57333.33 & 66666.67 & 76000 & 85333.33 & 94666.67 & \\
\hline 30.97376 & & & & & & & & & & & & \\
\hline & Mass Fu & 800 & 1500 & 2200 & 2900 & 3600 & 4300 & 5000 & 5700 & 6400 & 7100 & \\
\hline 21.75 & Mass Hyd. OII & 12432 & 23310 & 34189 & 45067 & 55945 & 66823 & 77702 & 88580 & 99458 & 110336 & \\
\hline 20.22 & Mass Total & 13232 & 24810 & 36389 & 47967 & 59545 & 71123 & 82702 & 94280 & 105858 & 117436 & \\
\hline 4 & & & & & & & & & & & & \\
\hline 1 & $\mathrm{HIPU}$ & 224.59 & 224.59 & 224.59 & 224.59 & 224.59 & 224.59 & 224.59 & 224.59 & 224.59 & 224.59 & OUTPUT \\
\hline & & & & & & & & & & & & \\
\hline 19.6 & Density & 1.240523 & 1.240523 & 1.240523 & 1.240523 & 1.240523 & 1.240523 & 1.240523 & 1.240523 & 1.240523 & 1.240523 & OUTPUT \\
\hline 1.17 & Densily Pu & 0.075000 & 0.075000 & 0.075000 & 0.075000 & 0.075000 & 0.075000 & 0.076000 & 0.075000 & 0.075000 & 0.075000 & \\
\hline & & & & & & & & & & & & \\
\hline$w t \% H$ & $1001.50 \mathrm{c}$ & -0.057255 & -0.057255 & -0.057255 & -0.057255 & -0.057255 & -0.057255 & -0.057255 & -0.057255 & .0 .057255 & -0.057255 & OUTPUT \\
\hline WE\% C & $6000.50 \mathrm{c}$ & -0.634261 & -0.634261 & -0.634261 & $-0.63426+1$ & -0.634261 & -0.634261 & -0.634261 & -0.634261 & -0.634261 & -0.634261 & OUTPUT \\
\hline wt\% O & $8016.50 \mathrm{c}$ & -0.167135 & -0.167135 & -0.167135 & -0.167135 & -0.167135 & -0.167135 & -0.167135 & -0.167135 & .0 .167135 & -0.167135 & OUTPUT \\
\hline$w+\% \mathrm{P}$ & $15031.50 \mathrm{c}$ & -0.080891 & -0.080891 & -0.080891 & -0.080891 & -0.080891 & -0.080891 & -0.080891 & -0.080891 & -0.080891 & -0.080891 & OUTPUT \\
\hline$w t \%{ }^{2 n} \mathrm{Pu}$ & $94239.55 \mathrm{c}$ & -0.060458 & -0.060458 & -0.060458 & .0 .060458 & .0 .060458 & -0.060458 & -0.060458 & -0.060458 & -0.060458 & -0.060458 & OUTPUT \\
\hline$w^{1} \%{ }^{200} \mathrm{Pu}$ & 94240.500 & 0.000000 & 0.000000 & 0.000000 & 0.000000 & 0.000000 & 0.000000 & 0.000000 & 0.000000 & 0.000000 & 0.000000 & OUTPUT \\
\hline & Sum & -1 & -1 & -1 & -1 & -1 & -1 & -1 & -1 & $\begin{array}{r}-1 \\
\end{array}$ & -1 & \\
\hline & & & & & & & & & & & & \\
\hline & Sphere $(\mathrm{cm})$ & 13.655681 & 16.838903 & $19.131 \mathrm{~B} 7 \mathrm{~B}$ & 20.977290 & 22.545033 & 23.920644 & 25.153980 & 26.276952 & 27.311363 & 28.272844 & OUTPUT \\
\hline & Sph. 1"Ref cm & 16.195681 & 19.378903 & 21.671878 & 23.517290 & 25.085033 & 26.460644 & 27.693980 & 28.816962 & 29.851363 & 30.812844 & OUTPUT \\
\hline & Sph. $12^{*}$ Ref cm & 44.135661 & 47.318903 & 49.611878 & 51.457290 & 53.025033 & 64.400644 & 55.633980 & 56.756962 & 57.791363 & 58.752844 & OUTPUT \\
\hline & & & & & & & & & & & & \\
\hline W\% $\mathbf{H}$ & $1001.50 \mathrm{c}$ & -0.060939 & -0.060939 & -0.060939 & -0.060939 & -0.060939 & -0.060939 & 0.060939 & -0.060939 & -0.060939 & -0.060939 & OUTPUT \\
\hline$w 1 \% \mathrm{C}$ & $6000.50 \mathrm{c}$ & -0.675075 & -0.675075 & -0.675075 & -0.675075 & -0.675075 & -0.675075 & -0.675075 & -0.675075 & .0 .675075 & -0.675075 & OUTPUT \\
\hline wt\%o & $8016.50 \mathrm{C}$ & -0.177990 & -0.177890 & -0.177890 & -0.177990 & -0.177890 & -0.177890 & 0.177890 & -0.177890 & 0.177890 & -0.177890 & OUTPUT \\
\hline$w t \% P$ & $15031.50 \mathrm{c}$ & -0.086096 & -0.086096 & -0.086096 & -0.086096 & -0.086096 & -0.086096 & -0.086096 & -0.086096 & -0.086096 & -0.086096 & OUTPUT \\
\hline & Sum & -1 & -1 & -1 & -1 & -1 & -1 & -1 & -1 & -1 & -1 & \\
\hline
\end{tabular}


Table D-5. MCNP Composition and Dimensions for Pu-Hydraulic Fluid $3.000 \mathrm{~g} / \mathrm{cm}^{3}$

Input is $\mathrm{Pu}(\mathrm{g} / \mathrm{L})$, Pu Mass ( $\mathrm{g}$ ) (10 evenly spaced), Output is MCNP composition, sphere dimensions

\begin{tabular}{|c|c|c|c|c|c|c|c|c|c|c|c|c|}
\hline \multicolumn{13}{|c|}{ MCNP Composition and Dimensions for Pu-Hydraulic Fluid $3.000 \mathrm{~g} / \mathrm{cm}^{3}$} \\
\hline 239.0522 & \multicolumn{2}{|c|}{$\mathrm{Pu}=\mathrm{C} 20.22 \mathrm{H} 21.75 \mathrm{O} 4 \mathrm{P}$} & \multirow[b]{2}{*}{0} & \multirow[b]{2}{*}{0} & \multirow[b]{2}{*}{0} & \multirow{2}{*}{0} & \multirow[b]{2}{*}{0} & \multirow[b]{2}{*}{0} & \multirow[b]{2}{*}{0} & \multirow[b]{2}{*}{0} & \multirow[b]{2}{*}{0} & \multirow[b]{2}{*}{ INPUT } \\
\hline 240.0540 & $200 \mathrm{Pu} / \mathrm{Pu}$ wt\% & 0 & & & & & & & & & & \\
\hline $\mathrm{H}$ & Mass Pu & 6000 & 12000 & 18000 & 24000 & 30000 & 36000 & 42000 & 48000 & 54000 & 60000 & INPUT \\
\hline 1.00797 & $\mathrm{Pu}\left(\mathrm{g} \mathrm{Pu} / \mathrm{cm}^{\wedge} 3\right)$ & 3.000 & 3.000 & 3.000 & 3.000 & 3.000 & 3.000 & 3.000 & 3.000 & 3.000 & 3.000 & INPUT \\
\hline C & Pu (grams/L) & 3000 & 3000 & 3000 & 3000 & 3000 & 3000 & 3000 & 3000 & 3000 & 3000 & \\
\hline \multicolumn{13}{|c|}{$\begin{array}{l}12.0111 \\
\end{array}$} \\
\hline $\mathrm{O}$ & Vol Pu $\left(\mathrm{cm}^{\wedge} 3\right)$ & 306.1224 & 612.2449 & 918.3673 & 1224.49 & 1530.612 & 1836.735 & 2142.857 & 2448,98 & 2755.102 & 3061.224 & \\
\hline 15.9994 & Vol Hyd. Oil & 1693.878 & 3387.755 & 5081.633 & 6775.51 & 8469.388 & 10163.27 & 11857.14 & 13551.02 & 15244.9 & 16938.78 & \\
\hline $\mathrm{P}$ & Vol. Total & 2000 & 4000 & 6000 & 8000 & 10000 & 12000 & 14000 & 16000 & 18000 & 20000 & \\
\hline \multicolumn{13}{|c|}{30.97376} \\
\hline & Mass Pu & 6000 & 12000 & 18000 & 24000 & 30000 & 36000 & 42000 & 48000 & 54000 & 60000 & \\
\hline 21.75 & Mass Hyd. Oil & 1982 & 3964 & 5946 & 7927 & 9909 & 11891 & 13873 & 15855 & 17837 & 19818 & \\
\hline 20.22 & Mass Total & 7982 & 15964 & 23946 & 31927 & 39909 & 47891 & 55873 & 63855 & 71837 & 79818 & \\
\hline \multicolumn{13}{|c|}{4} \\
\hline \multirow[t]{2}{*}{1} & \multirow[t]{2}{*}{$\mathrm{H} / \mathrm{Pu}$} & 4.77 & 4.77 & 4.77 & 4.77 & 4.77 & 4.77 & 4.77 & 4.77 & 4.77 & 4.77 & OUTPUT \\
\hline & & & & & & & & & & & & \\
\hline 19.6 & \multirow{2}{*}{$\begin{array}{l}\text { Density } \\
\text { Density Pu }\end{array}$} & 3.990918 & 3.990918 & 3.990918 & 3.990918 & 3.990918 & 3.990918 & 3.990918 & 3.990918 & 3.990918 & 3.990918 & \multirow{2}{*}{ OUTPUT } \\
\hline \multirow{2}{*}{1.17} & & 3.000000 & 3.000000 & 3.000000 & 3.000000 & 3.000000 & \multirow{2}{*}{3.000000} & \multirow{2}{*}{3.000000} & 3.000000 & 3.000000 & 3.000000 & \\
\hline & Density Pu & & & & & & & & & & & \\
\hline $\mathrm{wt} \% \mathrm{H}$ & $1001.50 \mathrm{c}$ & -0.015131 & -0.015131 & -0.015131 & -0.015131 & -0.015131 & -0.015131 & -0.015131 & 0.015131 & -0.015131 & -0.015131 & OUTPUT \\
\hline $\mathrm{w} t \% \mathrm{C}$ & $6000.50 \mathrm{c}$ & -0.167617 & -0.167617 & -0.167617 & -0.167617 & -0.167617 & -0.167617 & -0.167617 & -0.167617 & -0.167617 & -0.167617 & OUTPUT \\
\hline $\mathrm{wt} \% \mathrm{O}$ & $8016.50 \mathrm{c}$ & -0.044169 & -0.044169 & -0.044169 & -0.044169 & -0.044169 & -0.044169 & -0.044169 & -0.044169 & -0.044169 & -0.044169 & OUTPUT \\
\hline $\mathrm{wt} \% \mathrm{P}$ & $15031.50 \mathrm{c}$ & -0.021377 & -0.021377 & -0.021377 & -0.021377 & -0.021377 & -0.021377 & -0.021377 & -0.021377 & -0.021377 & $=0.021377$ & OUTPUT \\
\hline $\mathrm{wt} \%{ }^{200} \mathrm{Pu}$ & $94239.55 \mathrm{c}$ & $=0.751707$ & $=0.751707$ & -0.751707 & -0.751707 & -0.751707 & $=0.751707$ & $=0.751707$ & $=0.751707$ & $=0.751707$ & $=0.751707$ & OUTPUT \\
\hline $\mathrm{w} \% \%^{200} \mathrm{Pu}$ & $94240.50 \mathrm{c}$ & 0.000000 & 0.000000 & 0.000000 & 0.000000 & 0.000000 & 0.000000 & 0.000000 & 0.000000 & 0.000000 & 0.000000 & OUTPUT \\
\hline & Sum & -1 & -1 & -1 & -1 & -1 & -1 & -1 & -1 & -1 & -1 & \\
\hline & & & & & & & & & & & & \\
\hline & Sphere $(\mathrm{cm})$ & 7.815926 & 9.847450 & 11.272517 & 12.407010 & 13.365046 & 14.202481 & 14.951329 & 15.631853 & 16.257782 & 16.838903 & OUTPUT \\
\hline & Sph. 1"Ref cm & 10.355926 & 12.387450 & 13.812517 & 14.947010 & 15.905046 & 16.742481 & 17.491329 & 18.171853 & 18.797782 & 19.378903 & OUTPUT \\
\hline & Sph. 12" Ref cm & 38.295926 & 40.327450 & 41.752517 & 42.887010 & 43.845046 & 44.682481 & 45.431329 & 46.111853 & 46.737782 & 47.318903 & OUTPUT \\
\hline & & & & & & & & & & & & \\
\hline $\mathrm{wt} \% \mathrm{H}$ & $1001.50 c$ & -0.060939 & -0.060939 & -0.060939 & -0.060939 & -0.060939 & -0.060939 & -0.060939 & $=0.060939$ & -0.060939 & 0.060939 & OUTPUT \\
\hline$w t \%$ C & $6000.50 \mathrm{c}$ & -0.675075 & -0.675075 & -0.675075 & -0.675075 & -0.675075 & -0.675075 & -0.675075 & -0.675075 & -0.675075 & -0.675075 & OUTPUT \\
\hline$w 1 \% 0$ & $8016.50 c$ & -0.177890 & -0.177890 & -0.177890 & -0.177890 & -0.177890 & $=0.177890$ & $=0.177890$ & $=0.177890$ & -0.177890 & $=0.177890$ & OUTPUT \\
\hline$w t \% P$ & $15031.50 \mathrm{c}$ & -0.086096 & -0.086096 & -0.086096 & -0.086096 & -0.086096 & -0.086096 & -0.086096 & -0.086096 & -0.086096 & $=0.086096$ & OUTPUT \\
\hline & Sum & -1 & -1 & -1 & -1 & -1 & -1 & -1 & \begin{tabular}{r|}
-1 \\
\end{tabular} & -1 & -1 & \\
\hline
\end{tabular}


Criticality Curves for Plutonium Hydraulic Fluid Mixtures

HNF-33756, Rev. 0

Representative MCNP input files are included.

Hyoil00RN00003m19000.inp (Spherical Pu-hydraulic fluid $3 \mathrm{~g} / \mathrm{L}, 19,000 \mathrm{~g} \mathrm{Pu}$ )

Hyoil00RF00075m02900.inp (Spherical Pu-hydraulic fluid $75 \mathrm{~g} / \mathrm{L}, 2,900 \mathrm{~g} \mathrm{Pu}$ )

Hyoil00RB03000m18000.inp (Spherical Pu-hydraulic fluid 3,000 g/L, 18,000 g Pu)

\section{Hyoil00RN00003m19000.inp \\ message:}

$\begin{array}{rclll}\text { Pu } & 0.003 & \mathrm{~g} / \mathrm{cm} 3 & 19000 & \text { grams } \\ 1 & 1 & -1.172821 & -1 & \\ 2 & 3 & -1.17 & -2 & 1 \\ 3 & 3 & -1.29 \mathrm{E}-3 & -3 & 2 \\ 4 & 0 & & & 3\end{array}$
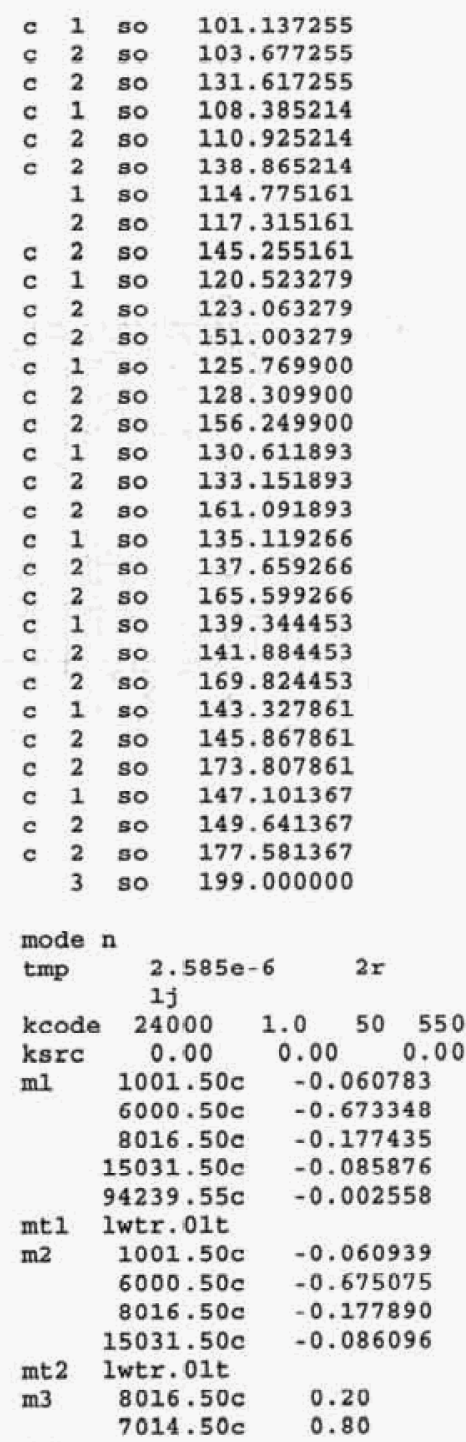

totnu

ctme 14480 .

print $\quad 30 \quad 40 \quad 60110126 \quad 140 \quad 170$

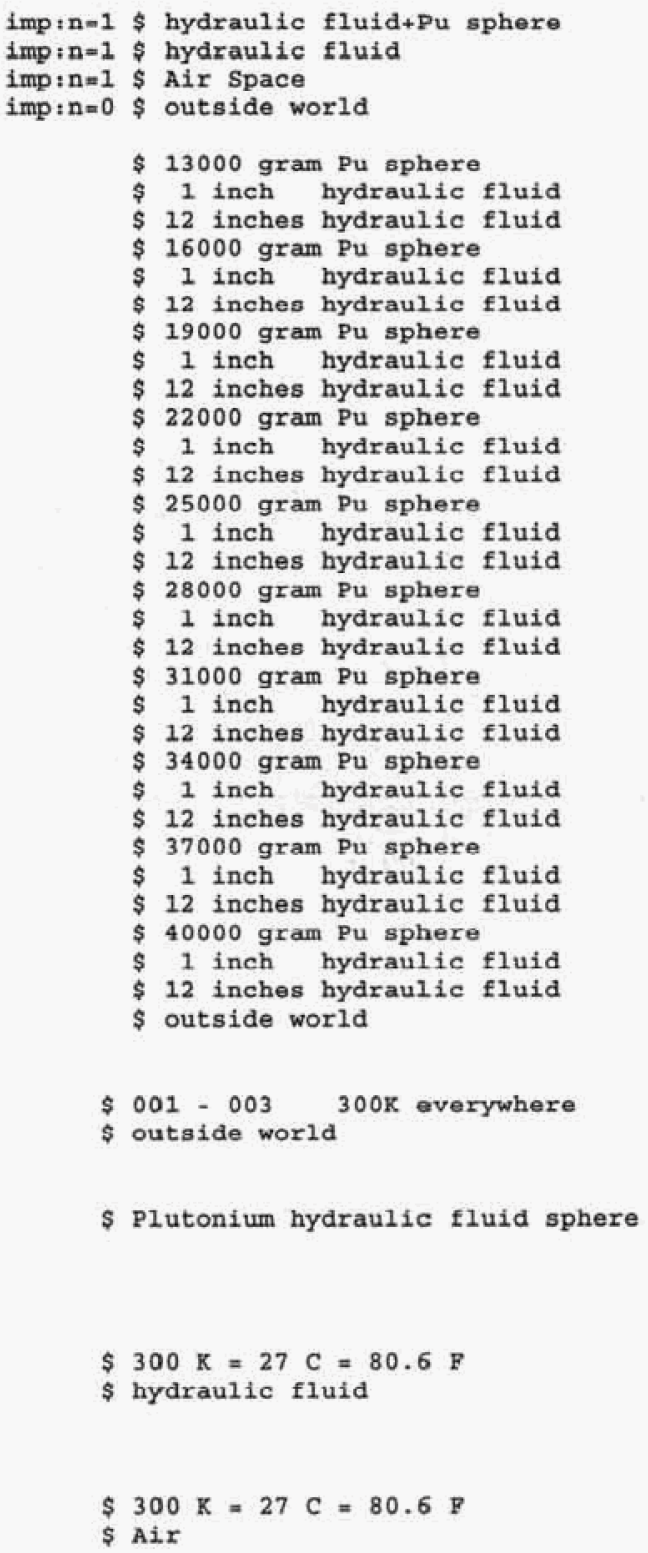


Criticality Curves for Plutonium Hydraulic Fluid Mixtures

HNF-33756, Rev. 0

\section{Hyoil00RF00075m02900.inp \\ message:}

$\begin{array}{ccccc}\text { Pu } & 0.075 & \mathrm{~g} / \mathrm{cm} 3 & 2900 & \text { grams } \\ 1 & 1 & -1.240523 & -1 & \\ 2 & 3 & -1.17 & -2 & 1 \\ 3 & 3 & -1.29 \mathrm{E}-3 & -3 & 2 \\ 4 & 0 & & & 3\end{array}$

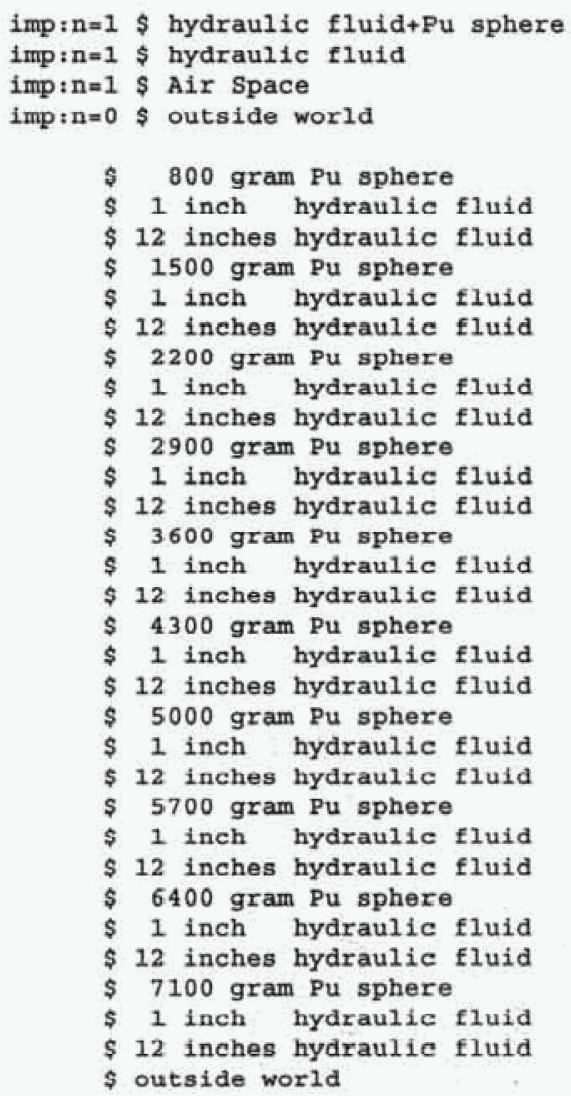

\$ 800 gram Pu sphere

$\$ 1$ inch hydraulic fluid

\$ 12 inches hydraulic fluid

$\$ 1500$ gram Pu sphere

\$ 1 inch hydraulic fluid

$\$ 12$ inches hydraulic fluid

\$2200 gram Pu sphere

$\$ 1$ inch hydraulic fluid

\$ 12 inches hydraulic fluid

\$ 2900 gram Pu sphere

$\$ 1$ inch hydraulic fluid

$\$ 12$ inches hydraulic fluid

\$3 3600 gram Pu sphere

$\$ 1$ inch hydraulic fluid

$\$ 12$ inches hydraulic fluid

\$ 4300 gram Pu sphere

$\$ 1$ inch hydraulic fluid

$\$ 12$ inches hydraulic fluid

\$ 5000 gram Pu sphere

$\$ 1$ inch hydraulic fluid

$\$ 12$ inches hydraulic fluid

\$ 5700 gram Pu sphere

$\$ 1$ inch hydraulic fluid

$\$ 12$ inches hydraulic fluid

$\$ 6400$ gram Pu sphere

$\$ 1$ inch hydraulic fluid

\$ 12 inches hydraulic fluid

$\$ 7100$ gram Pu sphere

$\$ 1$ inch hydraulic fluid

\$ 12 inches hydraulic fluid

$\$$ outside world

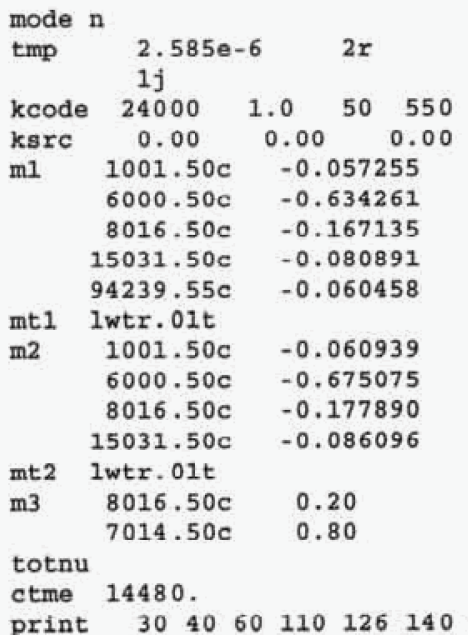

$\$ 001-003 \quad 300 \mathrm{~K}$ everywhere

$\$$ outside world

\$ Plutonium hydraulic fluid sphere

$\$ 300 \mathrm{~K}=27 \mathrm{C}=80.6 \mathrm{~F}$

$\$$ hydraulic fluid

$\$ 300 \mathrm{~K}=27 \mathrm{C}=80.6 \mathrm{P}$

$\$$ Air 
Criticality Curves for Plutonium Hydraulic Fluid Mixtures

HNF-33756, Rev. 0

\section{Hyoil00RB03000m18000.inp \\ message:}

$\begin{array}{rlllll}\text { Pu } & 3.000 \mathrm{~g} / \mathrm{cm} 3 & 18000 & \mathrm{grams} & \\ 1 & 1 & -3.990918 & -1 & \\ 2 & 3 & -1.29 \mathrm{E}-3 & -2 & 1 \\ 3 & 3 & -1.29 \mathrm{E}-3 & -3 & 2 \\ 4 & 0 & & & 3\end{array}$

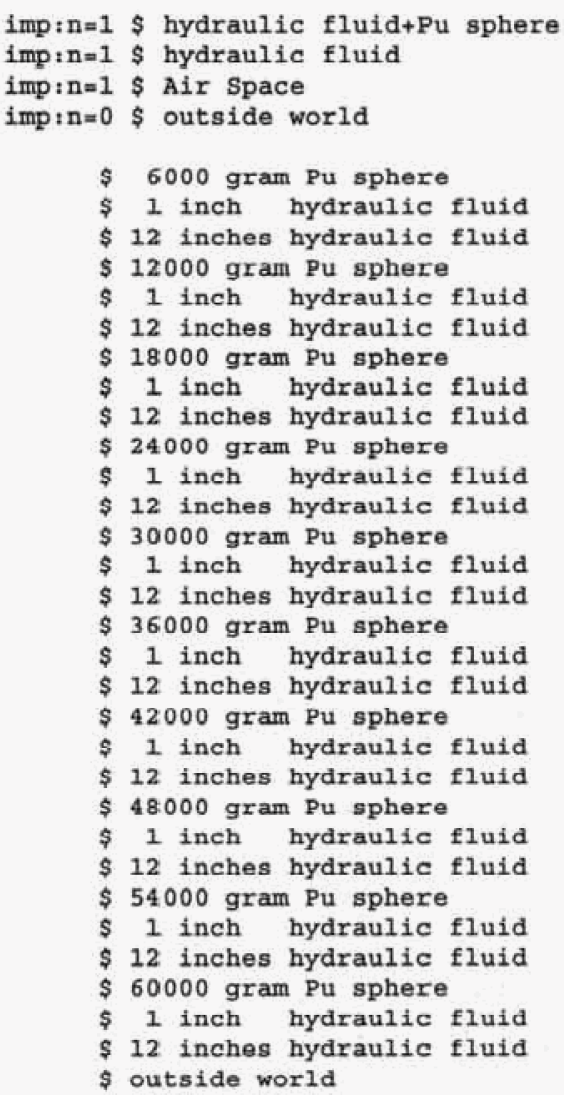




\section{Criticality Curves for Plutonium Hydraulic Fluid Mixtures HNF-33756, Rev. 0}

These hydraulic fluid MCNP results for FYRQUEL ${ }^{\otimes} 220$ are for $0 \mathrm{wt} \%{ }^{240} \mathrm{Pu}$ " 00 ", the first third "RB" is for bare reflection geometry, the second third "RF" are for 12 inch hydraulic fluid reflection, and the final third, "RN" are for 1 inch hydraulic fluid reflection. The concentration in grams per liter is given before the " $\mathrm{m}$ ", " 00002 " is for 2 grams plutonium per liter. The mass in grams plutonium is given after the " $\mathrm{m}$ ", " 08000 " is for 8,000 grams plutonium in the sphere.

\begin{tabular}{|c|c|c|}
\hline ase Desig & Keff & $\pm \sigma_{\text {cale }}$ \\
\hline $02 \mathrm{m04000}$ & 0.74941 & \\
\hline 6000 & & \\
\hline hyoil 100 RB $00002 \mathrm{~m} 28000$ & & \\
\hline hyoilooRB $00002 \mathrm{~m} 40000$ & & \\
\hline hyoil00RB00002m52000 & 0.82105 & \\
\hline hyoilo0RB $00002 \mathrm{~m} 64000$ & 0.82356 & \\
\hline hyoil 100 RB $00002 \mathrm{~m} 76000$ & 0.82513 & 007 \\
\hline hyoilo0RBOOC & 0.82629 & \\
\hline YOil 00 RB $00002 m A A 000$ & 0.82 & \\
\hline YOil 00 RB $00002 \mathrm{mBB} 000$ & 0.82 & \\
\hline $53 \mathrm{~m} 13000$ & $0.9 ?$ & \\
\hline 6000 & 0.9 & \\
\hline 0000 & 0.9 & \\
\hline 2000 & 0.9 & 0.0 \\
\hline hyoilo & 0.9 & \\
\hline hyoilo & 0.9 & \\
\hline hyoilo & 0.9 & \\
\hline hyoiloo & 0.9 & 0.0 \\
\hline hyoilod & 0.9 & 0.0 \\
\hline yoiloc & 0.9 & \\
\hline yoiloc & 0.5 & 0.0 \\
\hline 10110 & 0.7 & 0.0 \\
\hline 1yoilo & 0.8 & \\
\hline yoilo & 0.8 & 0.0 \\
\hline yoilo & 0.9 & 0.0 \\
\hline hyoilo & 0.9 & 0.0 \\
\hline hyoilo & 0.9 & 0. \\
\hline hyoilo & 0.9 & \\
\hline yoilo & 1.0 & \\
\hline yoilo & 1.01851 & 0.00 \\
\hline 0110 & 0.6 & \\
\hline 5110 & 0.8 & 0. \\
\hline yoi10 & 0.9 & 0.0 \\
\hline hyoilo & 0.9 & \\
\hline hyoilo & 1.0 & \\
\hline hyoilo & 1.0 & 0. \\
\hline hyoilo & 1.0 & 0.0 \\
\hline hyoilo & 1.05 & 0.00 \\
\hline yoil100 & 1.11 & 0.0 \\
\hline 101100 & 1.13 & 0.00 \\
\hline 10110 & 0.5 & 0. \\
\hline yoilo & 0.75 & \\
\hline hyoilo & 0.86 & \\
\hline hyoilo & 0.9 & 0.0 \\
\hline hyoilo0 & 1.00 & 0.00 \\
\hline hyoilo & 1.0 & 0.0 \\
\hline hyoiloc & 1.08 & 0.0 \\
\hline yoiloc & 1.11 & 0.00 \\
\hline yoil100 & 1.142 & 0.00 \\
\hline yoil100 & 1.16 & \\
\hline yoil $00 R B 00030 \mathrm{m0} 0300$ & 0.460 & 0.000 \\
\hline YOI100RBO0O & 0.70089 & 0.00025 \\
\hline hyoiloo & 0.834 & \\
\hline
\end{tabular}

\begin{tabular}{|c|c|c|}
\hline & & \\
\hline hyO1100RB00030m01780 & & \\
\hline hyoilo0RBO0030m02150 & & \\
\hline $\mathrm{B} 00030 \mathrm{~m} 02520$ & 1.0 & \\
\hline hyO1100RBO0030m02890 & 1.12141 & \\
\hline hyo1100RB00030m03260 & 1.15065 & \\
\hline hyoil00RB00030m03630 & 1.17670 & 0.00026 \\
\hline $\mathrm{B} 00050 \mathrm{~m} 00700$ & 0.61381 & 0.00026 \\
\hline $\mathrm{B} 00050 \mathrm{~m} 01200$ & 0.78102 & 0.00027 \\
\hline hyoilo0RB00050m01700 & 0.88879 & 0.00027 \\
\hline $\mathrm{BO} 0050 \mathrm{m02}$ & 0.96592 & 0.000 \\
\hline $\mathrm{B} 00050 \mathrm{m02}$ & 1.02405 & 0.000 \\
\hline $\mathrm{B} 00050 \mathrm{~m} 03200$ & 1.07232 & 0.000 \\
\hline $\mathrm{B} 00050 \mathrm{m0} 3700$ & 1.11132 & 0.000 \\
\hline hyoilo & & 0.00 \\
\hline 00050 & 1.17389 & 0.00 \\
\hline hyoilo & 1.19850 & 0.00026 \\
\hline hyoilo & 0.56517 & 0.0002 \\
\hline hyoilo & 0.75959 & 0.00 \\
\hline hyoilo & 0.87855 & 0.00 \\
\hline hyoilo & 0.96248 & 0.00 \\
\hline hyoilo & 1.025 & \\
\hline hyoilo & 1.07586 & \\
\hline hyoilo & 1.11739 & 0.000 \\
\hline hyoilo & 1.15235 & 0.000 \\
\hline 1yoilo & 1.18227 & 0.0002 \\
\hline hyoilo & 1.20782 & 0.00 \\
\hline hyoilo & 0.69006 & 0.00 \\
\hline hyoilo & 0.83719 & 0.06 \\
\hline hyoilo & 0.934 & 0.00 \\
\hline hyoilo & 1.00757 & 0.00 \\
\hline hyoilo & 1.06383 & 0.00 \\
\hline hyoilo & 1.10890 & 0.0002 \\
\hline $800100 \mathrm{m06900}$ & 1.14675 & 0.000 \\
\hline hyoilo & 1.17863 & 0.00 \\
\hline yoi10 & 1.20548 & 0.00 \\
\hline hyoilo & 1.23096 & \\
\hline 00 & 0.60891 & 0.00 \\
\hline 0020 & 0.78 & 0.00 \\
\hline hyoilo & 0.90376 & 0.00 \\
\hline $300200 \mathrm{~m}$ & 0.98513 & 0.0002 \\
\hline $300200 \pi$ & 1.04719 & 0.0002 \\
\hline $\mathrm{BO0200 \textrm {m } 1 0}$ & 1.09713 & 0.0002 \\
\hline $\mathrm{B} 00200 \mathrm{~m} 11600$ & 1.13770 & 0.0002 \\
\hline 3002000 & 1.17282 & 0.00 \\
\hline hyoilo & 1.20261 & \\
\hline hyoiloc & 1.22871 & 0.00 \\
\hline $\mathrm{BO} 0300 \mathrm{m03000}$ & 0.63345 & 0.0002 \\
\hline $\mathrm{RBO} 0300 \mathrm{m05} 100$ & 0.79620 & 0.0002 \\
\hline $\mathrm{RB} 00300 \mathrm{m07200}$ & 0.90322 & 0.0002 \\
\hline $2 B 00300 \mathrm{m09300}$ & 0.98139 & 0.0002 \\
\hline $\mathrm{B} 00300 \mathrm{~m} 11400$ & 1.04116 & 0.00 \\
\hline hyoil 100 RBO $0300 \mathrm{~m} 13500$ & 1.09028 & 0.00 \\
\hline hyoiloorBo $0300 \mathrm{~m} 15600$ & 1.130 & \\
\hline
\end{tabular}




\section{Criticality Curves for Plutonium Hydraulic Fluid Mixtures HNF-33756, Rev. 0}

\begin{tabular}{|c|c|c|}
\hline hyoilooRB $00300 \mathrm{~m} 17700$ & 1.16452 & 0.00030 \\
\hline hyoil00RB00300m19800 & 1.19443 & 0.00029 \\
\hline hyoil00RB $00300 \mathrm{~m} 21900$ & 1.21993 & 0.00028 \\
\hline hyoilooRB $00500 \mathrm{m04000}$ & 0.60410 & 0.00025 \\
\hline hyoil00RB00500m07000 & 0.77315 & 0.00028 \\
\hline hyoilo0RB $00500 \mathrm{~m} 10000$ & 0.88315 & 0.00028 \\
\hline hyoil00RB $00500 \mathrm{~m} 13000$ & 0.96354 & 0.00028 \\
\hline hyoil00RB00500m16000 & 1.02568 & 0.00029 \\
\hline hyoil00RB00500m19000 & 1.07563 & 0.00028 \\
\hline hyoil 00 RB $00500 \mathrm{~m} 22000$ & 1.11762 & 0.00029 \\
\hline hyoilo0RB00500m 25000 & 1.15311 & 0.00030 \\
\hline hyOil00RB $00500 \mathrm{~m} 28000$ & 1.18388 & 0.00028 \\
\hline hyoil00RB00500m31000 & 1.21075 & 0.00029 \\
\hline hyoilooRB01000m05500 & 0.56629 & 0.00026 \\
\hline hyoilo0RB $01000 \mathrm{~m} 10000$ & 0.74070 & 0.00025 \\
\hline hyoilo0RB $01000 \mathrm{~m} 14500$ & 0.85427 & 0.00028 \\
\hline hyoil00RB01000m19000 & 0.93749 & 0.00029 \\
\hline hyOil00RB01000m23500 & 1.00243 & 0.00029 \\
\hline hyoil00RB $01000 \mathrm{~m} 28000$ & 1.05477 & 0.00028 \\
\hline hyoil00RB01000m32500 & 1.09867 & 0.00029 \\
\hline hyoilooRB $01000 \mathrm{~m} 37000$ & 1.13585 & 0.00029 \\
\hline hyoilo0RB $01000 \mathrm{~m} 41500$ & 1.16825 & 0.00028 \\
\hline hyoilo0RB01000m46000 & 1.19710 & 0.00029 \\
\hline hyoil00RB $02000 \mathrm{m0} 6000$ & 0.50874 & 0.00022 \\
\hline hyoil00RB $02000 \mathrm{~m} 12000$ & 0.69680 & 0.00024 \\
\hline hyoilo0RB $02000 \mathrm{~m} 18000$ & 0.81846 & 0.00026 \\
\hline hyoil00RB02000m24000 & 0.90665 & 0.00027 \\
\hline hyOil00RB $02000 \mathrm{~m} 30000$ & 0.97544 & 0.00028 \\
\hline hyoil00RB02000m36000 & 1.03161 & 0.00028 \\
\hline hyoilo0RB $02000 \mathrm{~m} 42000$ & 1.07865 & 0.00028 \\
\hline hyoll00RB $02000 \mathrm{~m} 48000$ & 1.11913 & 0.00028 \\
\hline hyoilooRB $02000 \mathrm{~m} 54000$ & 1.15376 & 0.00028 \\
\hline hyoil00RB $02000 \mathrm{~m} 60000$ & 1.18448 & 0.00028 \\
\hline hyoil00RB03000m06000 & 0.49369 & 0.00018 \\
\hline hyoilo0RB $03000 \mathrm{~m} 12000$ & 0.67040 & 0.00022 \\
\hline hyoilooRB $03000 \mathrm{~m} 18000$ & 0.78772 & 0.00023 \\
\hline hyoil00RB0 $3000 \mathrm{~m} 24000$ & 0.87464 & 0.00026 \\
\hline hyoil00RB0 $3000 \mathrm{~m} 30000$ & 0.94364 & 0.00026 \\
\hline hyoil00RB03000m 36000 & 1.00009 & 0.00028 \\
\hline hyoil0oRB $03000 \mathrm{~m} 42000$ & 1.04787 & 0.00027 \\
\hline hyoil00RB $03000 \mathrm{~m} 48000$ & 1.08947 & 0.00028 \\
\hline hyoilo0RB $03000 \mathrm{~m} 54000$ & 1.12620 & 0.00028 \\
\hline hyoilo0RB $03000 \mathrm{~m} 60000$ & 1.15763 & 0.00029 \\
\hline hyoil00RB05000m05000 & 0.47803 & 0.00015 \\
\hline hyoil00RB $05000 \mathrm{ml} 0000$ & 0.63516 & 0.00019 \\
\hline hyoilooRB $05000 \mathrm{~m} 15000$ & 0.74254 & 0.00020 \\
\hline hyoil00RB0 $5000 \mathrm{~m} 20000$ & 0.82465 & 0.00021 \\
\hline hyoil00RB0 $5000 \mathrm{~m} 25000$ & 0.89130 & 0.00023 \\
\hline hyoilooRB $05000 \mathrm{~m} 30000$ & 0.94752 & 0.00024 \\
\hline hyoil00RB $05000 \mathrm{~m} 35000$ & 0.99502 & 0.00025 \\
\hline hyoilooRB $05000 \mathrm{~m} 40000$ & 1.03683 & 0.00024 \\
\hline hyoil00RB0 $5000 \mathrm{~m} 45000$ & 1.07413 & 0.00025 \\
\hline hyOil00RB0 $5000 \mathrm{~m} 50000$ & 1.10789 & 0.00027 \\
\hline hyoil00RB10000m06500 & 0.64938 & 0.00013 \\
\hline hyoil00RB $10000 \mathrm{m0} 9000$ & 0.72587 & 0.00014 \\
\hline hyoilo0RB10000m11500 & 0.78779 & 0.00015 \\
\hline hyoil00RB $10000 \mathrm{~m} 14000$ & 0.84045 & 0.00016 \\
\hline hyoil00RB10000m16500 & 0.88604 & 0.00018 \\
\hline hyoil00RB10000m19000 & 0.92720 & 0.00018 \\
\hline hYO1100RB10000m21500 & 0.96351 & 0.00018 \\
\hline hyoil00RB10000m24000 & 0.99641 & 0.00021 \\
\hline hyoilo0RB10000m26500 & 1.02750 & 0.00020 \\
\hline
\end{tabular}

\begin{tabular}{|c|c|c|}
\hline & & \\
\hline & & \\
\hline yoil100RB15000m06000 & 0.75219 & \\
\hline yoilooRB15000m07500 & 0.80648 & \\
\hline Yoil100RB15000m09000 & 0.85337 & \\
\hline & & \\
\hline & & \\
\hline & & \\
\hline yoilo & 0.99 & \\
\hline yoilo & & \\
\hline yoilor & 1.04906 & \\
\hline yoiloc & 0.69227 & \\
\hline yoilou & 0.75572 & \\
\hline yoilo & 0.80863 & \\
\hline 000 & & \\
\hline 000 & & \\
\hline$\overline{00}$ & & \\
\hline & & \\
\hline & & \\
\hline yoil & & \\
\hline roilc & & \\
\hline yoilo & & \\
\hline roilo & 0.80 & \\
\hline yoilo & 0.81 & \\
\hline & & \\
\hline & 0.82 & \\
\hline yo11 & 0.8 & \\
\hline yoil & 88 & \\
\hline 00 & & \\
\hline hyoilc & & \\
\hline hyoilo & 0.82 & \\
\hline hyoilo & & \\
\hline 00 & & \\
\hline hyoilo & 0.97 & \\
\hline hyoilo & 0.98 & \\
\hline & & \\
\hline yoillo & & \\
\hline hyoilo & & \\
\hline hyoil & & \\
\hline nyol10 & & \\
\hline hyoilo & & \\
\hline hyoilo & 0.71 & \\
\hline hyoiloc & 0.84 & \\
\hline ayoiloc & 0. & \\
\hline$y 0110$ & & \\
\hline hyoilo & & \\
\hline & & \\
\hline & & \\
\hline & & \\
\hline hyoilo & 1.04 & \\
\hline hyoilo & 1.05 & \\
\hline hyoilo & 0.82 & \\
\hline & & \\
\hline & & \\
\hline & & \\
\hline hyoilo & 1.09 & \\
\hline hyoiloc & 1.12 & \\
\hline hyoiloo & 1.148 & 0.00 \\
\hline hyoilo0 & 1.16745 & \\
\hline hyoi100 & 1.18 & \\
\hline hyo1100 & 1.196 & 0.000 \\
\hline hyoil 100 & 0.770 & \\
\hline
\end{tabular}




\section{Criticality Curves for Plutonium Hydraulic Fluid Mixtures HNF-33756, Rev. 0}

\begin{tabular}{|c|c|c|}
\hline hyoil00RF00020m00 & 0.93353 & 0.00024 \\
\hline hyOil00RF00020m00950 & 1.02527 & 0.00023 \\
\hline hyOil00RF00020m01250 & 1.08765 & 0.00023 \\
\hline hyoilooRF00020m01550 & 1.13331 & 0.00022 \\
\hline hyoil00RF00020m01850 & 1.16893 & 0.00023 \\
\hline hyOil00RF00020m02150 & 1.19799 & 0.00021 \\
\hline hyoil00RF 00020m02450 & 1.22161 & 0.00021 \\
\hline hyoilooRF00020m02750 & 1.24192 & 0.00021 \\
\hline hyoilooRF00020m03050 & 1.26029 & 0.00022 \\
\hline hyoilo0RF00030m00300 & 0.67939 & 0.00024 \\
\hline hyoilo0RF $00030 \mathrm{m00670}$ & 0.90184 & 0.00023 \\
\hline hyoilooRF00030m01040 & 1.01640 & 0.00024 \\
\hline hyoilooRF00030m01410 & 1.08902 & 0.00024 \\
\hline hyoil00RF00030m01780 & 1.14214 & 0.00023 \\
\hline hyOil00RF00030m02150 & 1.18252 & 0.00023 \\
\hline hyoilo0RF $00030 \mathrm{~m} 02520$ & 1.21530 & 0.00024 \\
\hline hyoil00RF00030m02890 & 1.24264 & 0.00024 \\
\hline hyoil00RF $00030 \mathrm{m0} 03260$ & 1.26419 & 0.00022 \\
\hline hyoilo0RF00030m03630 & 1.28452 & 0.00022 \\
\hline hyoil00RF $00050 \mathrm{m0} 0700$ & 0.83644 & 0.00026 \\
\hline hYoil00RF00050m01200 & 0.98385 & 0.00026 \\
\hline hyoil00RF00050m01700 & 1.07327 & 0.00025 \\
\hline hyoilo0RF00050m02200 & 1.13543 & 0.00024 \\
\hline hyoil00RF00050m02700 & 1.18215 & 0.00025 \\
\hline hyoilooRF00050m03200 & 1.21963 & 0.00025 \\
\hline hyoilo0RF00050m03700 & 1.24974 & 0.00024 \\
\hline hyoil00RF00050m04200 & 1.27456 & 0.00023 \\
\hline hyO1100RF00050m04700 & 1.29662 & 0.00023 \\
\hline hyoil00RF $00050 \mathrm{m05200}$ & 1.31584 & 0.00024 \\
\hline hyoil00RF00075m00800 & 0.79681 & 0.00024 \\
\hline hyoil00RF00075m01500 & 0.97220 & 0.00026 \\
\hline hyoil00RF $00075 \mathrm{m02200}$ & 1.07245 & 0.00024 \\
\hline hyoilooRF00075m02900 & 1.14018 & 0.00026 \\
\hline hyoil00RF $00075 \mathrm{m03600}$ & 1.19070 & 0.00026 \\
\hline hyoilo0RF00075m04300 & 1.23069 & 0.00024 \\
\hline hyoil00RF00075m05000 & 1.26252 & 0.00026 \\
\hline hyoil00RF $00075 \mathrm{~m} 05700$ & 1.28886 & 0.00026 \\
\hline hyoilooRF00075m06400 & 1.31157 & 0.00025 \\
\hline hyoilo0RF $00075 \mathrm{m07100}$ & 1.33129 & 0.00025 \\
\hline hyoilo0RF00100m01500 & 0.91452 & 0.00026 \\
\hline hyoil00RF00100m02400 & 1.04149 & 0.00026 \\
\hline hyol100RF00100m03300 & 1.12181 & 0.00025 \\
\hline hyoil00RF00100m04200 & 1.17987 & 0.00025 \\
\hline hyOil00RF00100m05100 & 1.22365 & 0.00025 \\
\hline hyO1100RF $00100 \mathrm{m06000}$ & 1.25924 & 0.00024 \\
\hline hyoilo0RF00100m06900 & 1.28840 & 0.00026 \\
\hline hyoil00RF00100m07800 & 1.31293 & 0.00024 \\
\hline hyoil00RF00100m08700 & 1.33462 & 0.00023 \\
\hline hyoilo0RF00100m09600 & 1.35249 & 0.00024 \\
\hline hyoilooRF 00200m02000 & 0.84336 & 0.00025 \\
\hline hyoilooRF00200m03600 & 1.00628 & 0.00028 \\
\hline hyoilooRF00200m05200 & 1.10232 & 0.00027 \\
\hline hyOil00RF00200m06800 & 1.16925 & 0.00026 \\
\hline hYOII00RF $00200 \mathrm{m0} 8400$ & 1.21848 & 0.00026 \\
\hline hyoil00RF00200m10000 & 1.25677 & 0.00026 \\
\hline hyoilooRF00200m11600 & 1.28970 & 0.00026 \\
\hline hyoil00RF00200m13200 & 1.31606 & 0.00024 \\
\hline hyoil00RF $00200 \mathrm{~m} 14800$ & 1.33878 & 0.00025 \\
\hline hyoilooRF $00200 \mathrm{~m} 16400$ & 1.35875 & 0.00025 \\
\hline hyOil00RF00300m03000 & 0.86739 & 0.00026 \\
\hline hyoil00RF $00300 \mathrm{m0} 0100$ & 1.01443 & 0.00027 \\
\hline hyoil00RF $00300 \mathrm{m0} 7200$ & 1.10462 & 0.00026 \\
\hline
\end{tabular}

\begin{tabular}{|l|l|l|l|}
\hline hYOilOORF00300m09300 & 1.16852 & 0.00026 \\
\hline
\end{tabular} \begin{tabular}{|l|l|l|}
\hline hYOil00RF00300m11400 & 1.21731 & 0.00026 \\
\hline
\end{tabular} \begin{tabular}{|l|l|l|l|}
\hline hYOil00RF00300m13500 & 1.25470 & 0.00027 \\
\hline
\end{tabular} \begin{tabular}{|l|l|l|l|}
\hline hYOilOORF00300m15600 & 1.28657 & 0.00027 \\
\hline
\end{tabular} \begin{tabular}{|l|l|l|}
\hline hyOilO0RF00300m17700 & 1.31308 & 0.00025 \\
\hline
\end{tabular} \begin{tabular}{|l|l|l|l|}
\hline hyOil00RF00300m19800 & 1.33585 & 0.00025 \\
\hline
\end{tabular} \begin{tabular}{|l|l|l|}
\hline hYOil 00RF00300m21900 & 1.35662 & 0.00024 \\
\hline
\end{tabular} \begin{tabular}{|l|l|l|l|}
\hline hyoil00RF00500m04000 & 0.83834 & 0.00026 \\
\hline
\end{tabular} \begin{tabular}{|l|l|l|l|}
\hline hyOil0ORF00500m07000 & 0.99560 & 0.00027 \\
\hline
\end{tabular} \begin{tabular}{|l|l|l|}
\hline hyoil00RF00500m10000 & 1.09080 & 0.00027 \\
\hline
\end{tabular} \begin{tabular}{|l|l|l|}
\hline hyoil00RF00500m13000 & 1.15763 & 0.00027 \\
\hline
\end{tabular} \begin{tabular}{|l|l|l|l|}
\hline hyoil00RF00500m16000 & 1.20842 & 0.00025 \\
\hline
\end{tabular} \begin{tabular}{|l|l|l|}
\hline hyOil0ORF00500m19000 & 1.24825 & 0.00026 \\
\hline
\end{tabular} \begin{tabular}{|l|l|l|}
\hline hyOil00RF00500m22000 & 1.28152 & 0.00026 \\
\hline
\end{tabular} \begin{tabular}{|l|l|l|l|}
\hline hYOil0ORF00500m25000 & 1.30840 & 0.00025 \\
\hline
\end{tabular} \begin{tabular}{|l|l|l|l|}
\hline hyoil00RF00500m28000 & 1.33340 & 0.00025 \\
\hline
\end{tabular} \begin{tabular}{|l|l|l|l|}
\hline hYOII OORFO0 $000 \mathrm{~m} 31000$ & 1.35370 & 0.00025 \\
\hline
\end{tabular} \begin{tabular}{|l|l|l|l|}
\hline hYOil00RF01000m05500 & 0.79525 & 0.00027 \\
\hline
\end{tabular} \begin{tabular}{|l|l|l|l|}
\hline hyOil00RF01000m10000 & 0.96581 & 0.00027 \\
\hline
\end{tabular} \begin{tabular}{|l|l|l|}
\hline hyoil00RF01000m14500 & 1.06841 & 0.00027 \\
\hline
\end{tabular} \begin{tabular}{|l|l|l|l|}
\hline hyoil00RF01000m19000 & 1.139997 & 0.00028 \\
\hline
\end{tabular} \begin{tabular}{|l|l|l|l|}
\hline hyoil 00 RF01000m23500 & 1.19432 & 0.00027 \\
\hline
\end{tabular} \begin{tabular}{|l|l|l|l|}
\hline hYOi100RF01000m28000 & 1.23 .764 & 0.00027 \\
\hline
\end{tabular} \begin{tabular}{|l|l|l|l|}
\hline hyoil 00RF01000m32500 & 1.27353 & 0.00028 \\
\hline
\end{tabular} \begin{tabular}{|l|l|l|}
\hline hyoil00RF01000m37000 & 1.30353 & 0.00026 \\
\hline
\end{tabular} \begin{tabular}{|l|l|l|l|}
\hline hyoil00RF01000m41500 & 1.32881 & 0.00027 \\
\hline
\end{tabular} \begin{tabular}{|l|l|l|}
\hline hYOil00RF01000m46000 & 1.35149 & 0.00027 \\
\hline
\end{tabular} \begin{tabular}{|l|l|l|}
\hline hYOil00RF02000m06000 & 0.71933 & 0.00025 \\
\hline
\end{tabular} \begin{tabular}{|l|l|l|l|}
\hline hyoil00RF02000m12000 & 0.91804 & 0.00027 \\
\hline
\end{tabular} \begin{tabular}{|l|l|l|l|}
\hline hyoil00RF02000m18000 & 1.03483 & 0.00028 \\
\hline
\end{tabular} \begin{tabular}{|l|l|l|}
\hline hyoil00RF02000m24000 & 1.11603 & 0.00028 \\
\hline
\end{tabular} \begin{tabular}{|l|l|l|}
\hline hyoilOORF02000m30000 & 1.17703 & 0.00028 \\
\hline
\end{tabular} \begin{tabular}{|l|l|l|}
\hline hyOil00RF02000m36000 & 1.22559 & 0.00027 \\
\hline
\end{tabular} \begin{tabular}{|l|l|l|l|}
\hline hYOil0ORF02000m42000 & 1.26546 & 0.00027 \\
\hline
\end{tabular} \begin{tabular}{|l|l|l|}
\hline hyOil00RF02000m48000 & 1.29896 & 0.00027 \\
\hline
\end{tabular} \begin{tabular}{|l|l|l|l|}
\hline hyoi100RF02000m54000 & 1.32827 & 0.00028 \\
\hline
\end{tabular} \begin{tabular}{|l|l|l|l|}
\hline hyoil00RF02000m60000 & 1.35390 & 0.00026 \\
\hline
\end{tabular} \begin{tabular}{|l|l|l|}
\hline hyoil00RF03000m06000 & 0.68401 & 0.00023 \\
\hline
\end{tabular} \begin{tabular}{|l|l|l|l|}
\hline hyoil00RF03000m12000 & 0.88153 & 0.00027 \\
\hline
\end{tabular} \begin{tabular}{|l|l|l|}
\hline hyOil00RF03000m18000 & 1.00012 & 0.00026 \\
\hline
\end{tabular} \begin{tabular}{|l|l|l|l|}
\hline hyOil0 ORF0 $3000 \mathrm{~m} 24000$ & 1.08484 & 0.00027 \\
\hline
\end{tabular} \begin{tabular}{|l|l|l|l|}
\hline hYO1100RF03000m30000 & 1.14874 & 0.00028 \\
\hline
\end{tabular} \begin{tabular}{|l|l|l|l|}
\hline hyoil 00 RF03000m36000 & 1.20067 & 0.00029 \\
\hline
\end{tabular} \begin{tabular}{|l|l|l|l|}
\hline hyO1100RF03000m42000 & 1.24342 & 0.00027 \\
\hline
\end{tabular} \begin{tabular}{|l|l|l|l|}
\hline hyoil $100 R F 03000 \mathrm{~m} 48000$ & 1.27905 & 0.00027 \\
\hline
\end{tabular} \begin{tabular}{|l|l|l|}
\hline hyoil 00RF03000m54000 & 1.31053 & 0.00027 \\
\hline
\end{tabular} \begin{tabular}{|l|l|l|}
\hline hyOil00RF03000m60000 & 1.33829 & 0.00027 \\
\hline
\end{tabular} \begin{tabular}{|l|l|l|}
\hline hyOil 00RF0 $5000 \mathrm{m0} 05000$ & 0.62849 & 0.00019 \\
\hline
\end{tabular} \begin{tabular}{|l|l|l|l|}
\hline hyoil 00 RF0 $0000 \mathrm{~m} 10000$ & 0.81737 & 0.00023 \\
\hline
\end{tabular} \begin{tabular}{|l|l|l|l|}
\hline hyoil 00RF0 $5000 \mathrm{~m} 15000$ & 0.93641 & 0.00023 \\
\hline
\end{tabular} \begin{tabular}{|l|l|l|l|}
\hline hYOil00RF0 $5000 \mathrm{~m} 20000$ & 1.02337 & 0.00025 \\
\hline
\end{tabular} \begin{tabular}{|l|l|l|l|}
\hline hyoil00RF05000m25000 & 1.09083 & 0.00026 \\
\hline
\end{tabular} \begin{tabular}{|l|l|l|}
\hline hyoil00RF05000m30000 & 1.14632 & 0.00027 \\
\hline
\end{tabular} \begin{tabular}{|l|l|l|l|}
\hline hyoil00RF0 $5000 \mathrm{~m} 35000$ & 1.19277 & 0.00025 \\
\hline
\end{tabular} \begin{tabular}{|l|l|l|l|}
\hline hYOil0 ORF0 $5000 \mathrm{~m} 40000$ & 1.23226 & 0.00026 \\
\hline
\end{tabular} \begin{tabular}{|l|l|l|}
\hline hyOil00RF05000m45000 & 1.26735 & 0.00026 \\
\hline
\end{tabular} \begin{tabular}{|l|l|l|l|}
\hline hyOil00RF0 $5000 \mathrm{~m} 50000$ & 1.29857 & 0.00026 \\
\hline
\end{tabular} \begin{tabular}{|l|l|l|l|}
\hline hyOil00RF10000m06500 & 0.77323 & 0.00018 \\
\hline
\end{tabular} \begin{tabular}{|l|l|l|l|}
\hline hyOil00RF10000m09000 & 0.86391 & 0.00018 \\
\hline
\end{tabular} \begin{tabular}{|l|l|l|l|}
\hline hYOil00RF10000m11500 & 0.93626 & 0.00021 \\
\hline
\end{tabular} \begin{tabular}{|l|l|l|l|}
\hline hyOil00RF10000m14000 & 0.99598 & 0.00022 \\
\hline
\end{tabular} \begin{tabular}{|l|l|l|l|}
\hline hyoil00RF10000m16500 & 1.04720 & 0.00021 \\
\hline
\end{tabular} 


\section{Criticality Curves for Plutonium Hydraulic Fluid Mixtures \\ HNF-33756, Rev. 0}

\begin{tabular}{|c|c|c|}
\hline hyOil00RF10000m19000 & 1.09229 & \\
\hline hyoil00RF10000m21500 & 1.13193 & 0.00024 \\
\hline hyoil00RF $10000 \mathrm{~m} 24000$ & 1.16723 & 0.00023 \\
\hline hyoil00RF10000m26500 & 1.19934 & 0.00023 \\
\hline hyoil00RF10000m29000 & 1.22965 & 0.00024 \\
\hline hyoilo0RF15000m04500 & 0.77772 & 0.00015 \\
\hline hyoil00RF15000m06000 & 0.85401 & 0.00017 \\
\hline hyoil00RF15000m07500 & 0.91757 & 0.00018 \\
\hline hyoil00RF15000m09000 & 0.97138 & 0.00018 \\
\hline hyoil100RF15000m10500 & 1.01827 & 0.00019 \\
\hline hyoil00RF15000m12000 & 1.06049 & 0.00020 \\
\hline hyoil0oRF $15000 \mathrm{~m} 13500$ & 1.09788 & 0.00020 \\
\hline hyoi.100RF $15000 \mathrm{~m} 15000$ & 1.13242 & 0.00021 \\
\hline hyoil00RF15000m16500 & 1.16346 & 0.00021 \\
\hline hyoil00RF15000m18000 & 1.19272 & 0.00021 \\
\hline hyoil00RF $19600 \mathrm{m03000}$ & 0.76164 & 0.00015 \\
\hline hyoil00RF19600m04000 & 0.83454 & 0.00015 \\
\hline hyOil00RF $19600 \mathrm{m0} 5000$ & 0.89536 & 0.00017 \\
\hline hyoil00RF $19600 \mathrm{m06000}$ & 0.94675 & 0.00017 \\
\hline hyOil00RF19600m07000 & 0.99223 & 0.00017 \\
\hline hyoil00RF19600m08000 & 1.03258 & 0.00018 \\
\hline hyoilo0RF $19600 \mathrm{m0} 9000$ & 1.06935 & 0.00020 \\
\hline hyoil00RF19600m10000 & 1.10252 & 0.00019 \\
\hline hyoilooRF $19600 \mathrm{~m} 11000$ & 1.13312 & 0.00018 \\
\hline hyOil00RF19600m12000 & 1.16157 & 0.00020 \\
\hline hyoilo0RN00002m04000 & 0.75285 & 0.00009 \\
\hline hyoil00RN00002m16000 & 0.80167 & 0.00007 \\
\hline hyoil00RN00002m28000 & 0.81285 & 0.00007 \\
\hline hyoilo0RN00002m40000 & 0.81831 & 0.00006 \\
\hline hyoilooRN00002m52000 & 0.82163 & 0.00006 \\
\hline hyoilo0RN00002m64000 & 0.82373 & 0.00006 \\
\hline hyoilo0RN00002m76000 & 0.82494 & 0.00006 \\
\hline hyoil00RN00002m88000 & 0.82693 & 0.00007 \\
\hline hyOil00RN00002mAAOOO & 0.82767 & 0.00006 \\
\hline hyOil00RN $00002 \mathrm{mBBO} 00$ & 0.82854 & 0.00007 \\
\hline hyoilo0RN00003m13000 & 0.96034 & 0.00009 \\
\hline hyoilo0RN00003m16000 & 0.96777 & 0.00009 \\
\hline hyoilo0RN00003m19000 & 0.97304 & 0.00009 \\
\hline hyoil00RN00003m22000 & 0.97728 & 0.00008 \\
\hline hyoilo0RN00003m25000 & 0.98081 & 0.00008 \\
\hline hyoilo0RN00003m28000 & 0.98377 & 0.00008 \\
\hline hyOil00RN00003m31000 & 0.98605 & 0.00007 \\
\hline hyoilooRN00003m34000 & 0.98781 & 0.00008 \\
\hline hyo1100RN00003m37000 & 0.98951 & 0.00008 \\
\hline hyoil 00 RN $00003 \mathrm{~m} 40000$ & 0.99106 & 0.00007 \\
\hline hyoilo0RN00005m00300 & 0.63122 & 0.00018 \\
\hline hyOil00RN00005m00600 & 0.77750 & 0.00018 \\
\hline hyoilo0RN00005m00900 & 0.85374 & 0.00017 \\
\hline hyoilo0RN00005m01200 & 0.90239 & 0.00017 \\
\hline hyOI100RN00005m01500 & 0.93755 & 0.00016 \\
\hline hyoil00RN00005m01800 & 0.96405 & 0.00016 \\
\hline hyollo0RN00005m02100 & 0.98495 & 0.00016 \\
\hline hyoil00RN00005m02400 & 1.00162 & 0.00016 \\
\hline hyoilo0RN00005m02700 & 1.01653 & 0.00016 \\
\hline hyOil00RN00005m03000 & 1.02849 & 0.00016 \\
\hline hyoil00RN00010m00400 & 0.72003 & 0.00023 \\
\hline hyoil00RN00010m00675 & 0.85330 & 0.00022 \\
\hline hyOil00RN00010m00950 & 0.93481 & 0.00022 \\
\hline hyoil00RN00010m01225 & 0.99016 & 0.00021 \\
\hline hyOil00RN00010m01500 & 1.03275 & 0.00022 \\
\hline hyOil00RN00010m01775 & 1.06578 & 0.00022 \\
\hline hyOil00RN00010m02050 & 1.09240 & 0.00021 \\
\hline
\end{tabular}

\begin{tabular}{|c|c|c|}
\hline & & \\
\hline & & \\
\hline & & \\
\hline 00350 & & \\
\hline hyoiloor & & 0 \\
\hline 0950 & & \\
\hline yoiloc & & \\
\hline 550 & & \\
\hline & & \\
\hline & & \\
\hline yoilo & & \\
\hline yoiloc & & \\
\hline yoilo & & \\
\hline yoilo & 0.52978 & \\
\hline yoilo & 0.76120 & \\
\hline yoilo & 0.88721 & \\
\hline yoilo & & \\
\hline yoilo & & \\
\hline & & \\
\hline & & 0.0 \\
\hline 390 & 1. & \\
\hline 60 & & \\
\hline roil & & \\
\hline yoi10 & & \\
\hline yoi100 & & \\
\hline yoilo & & \\
\hline yoilo & & \\
\hline yoilo & 1.067 & 0.0 \\
\hline 011 & 1. & \\
\hline 0110 & 1.1 & \\
\hline roilc & & \\
\hline yoilo & & \\
\hline yoilo & & \\
\hline yoilo & & \\
\hline yoilo & & \\
\hline yoilo & 0.9 & \\
\hline roilo & & \\
\hline 00 & & \\
\hline 00 & & \\
\hline 00 & & \\
\hline & & \\
\hline yoilo & 1.21 & \\
\hline yoilo & 1.23 & \\
\hline yoilo & 5666 & \\
\hline oilo & 0.8 & \\
\hline 10110 & & \\
\hline yoilo & 1. & \\
\hline 100 & 1. & \\
\hline & & \\
\hline hyoilo & 1.18 & \\
\hline yoilo & 1.21345 & \\
\hline yoilo & 1.23870 & \\
\hline yoi10 & 1.26160 & \\
\hline & & \\
\hline & & \\
\hline hyoiloc & & \\
\hline hyoi100F & 1.03569 & \\
\hline $00200 \mathrm{m0} 8400$ & 1.09364 & 0.00 \\
\hline $00200 \mathrm{~m} 10000$ & 1.13870 & 0.00 \\
\hline 1yoi100 & 1.17742 & 0.05 \\
\hline yoiloc & 1.20932 & 0.0 \\
\hline & & \\
\hline
\end{tabular}




\section{Criticality Curves for Plutonium Hydraulic Fluid Mixtures \\ HNF-33756, Rev. 0}

\begin{tabular}{|l|l|l|l|}
\hline hyoil 00RN00200m16400 & 1.26114 & 0.00027 \\
\hline
\end{tabular} \begin{tabular}{|l|l|l|l|}
\hline hyOil OORNO $0300 \mathrm{m0} 03000$ & 0.70331 & 0.00027 \\
\hline
\end{tabular} \begin{tabular}{|l|l|l|}
\hline hyOil OORNO0300m05100 & 0.85842 & 0.00029 \\
\hline
\end{tabular} \begin{tabular}{|l|l|l|l|}
\hline hyoil 0 ORNO0 $300 \mathrm{m07200}$ & 0.95969 & 0.00029 \\
\hline
\end{tabular} \begin{tabular}{|l|l|l|l|}
\hline hyoil 00 RN0 $0300 \mathrm{m09300}$ & 1.03187 & 0.00027 \\
\hline
\end{tabular} \begin{tabular}{|l|l|l|l|}
\hline hyoil OORN00300m11400 & 1.08833 & 0.00029 \\
\hline
\end{tabular} \begin{tabular}{|l|l|l|l|}
\hline hyoil OORNO0 $300 \mathrm{~m} 13500$ & 1.13344 & 0.00028 \\
\hline
\end{tabular} \begin{tabular}{|l|l|l|}
\hline hyoi1 OORNO0 $300 \mathrm{~m} 15600$ & 1.17115 & 0.00030 \\
\hline
\end{tabular} \begin{tabular}{|l|l|l|}
\hline hyoil OORNO0300m17700 & 1.20282 & 0.00029 \\
\hline
\end{tabular} \begin{tabular}{|l|l|l|}
\hline hyoil OORNO0 $300 \mathrm{~m} 19800$ & 1.23010 & 0.00027 \\
\hline
\end{tabular} \begin{tabular}{|l|l|l|l|}
\hline hyOil OORN00300m21900 & 1.25455 & 0.00029 \\
\hline
\end{tabular} \begin{tabular}{|l|l|l|}
\hline hyoiloORN00500m04000 & 0.67451 & 0.00026 \\
\hline
\end{tabular} \begin{tabular}{|l|l|l|l|}
\hline hyoil OORNO0 $500 \mathrm{m0} 07000$ & 0.83723 & 0.00028 \\
\hline
\end{tabular} \begin{tabular}{|l|l|l|l|}
\hline hyOi LORNO $0500 \mathrm{ml} 10000$ & 0.94163 & 0.00028 \\
\hline
\end{tabular} \begin{tabular}{|l|l|l|l|}
\hline hyOil100RNO0 $500 \mathrm{~m} 13000$ & 1.01690 & 0.00029 \\
\hline
\end{tabular} \begin{tabular}{|l|l|l|}
\hline hyoiloORNO0 $500 \mathrm{~m} 16000$ & 1.07421 & 0.00029 \\
\hline
\end{tabular} \begin{tabular}{|l|l|l|}
\hline hyOIIOORNO $0500 \mathrm{~m} 19000$ & 1.12179 & 0.00028 \\
\hline
\end{tabular} \begin{tabular}{|l|l|l|}
\hline hyOII OORNO $0500 \mathrm{~m} 22000$ & 1.16055 & 0.00029 \\
\hline
\end{tabular} \begin{tabular}{|l|l|l|l|}
\hline hyoil OORNO $0500 \mathrm{~m} 25000$ & 1.19353 & 0.00029 \\
\hline
\end{tabular} \begin{tabular}{|l|l|l|l|}
\hline hyO 1100 RNO0 $500 \mathrm{~m} 28000$ & 1.22126 & 0.00028 \\
\hline
\end{tabular} \begin{tabular}{|l|l|l|l|}
\hline hyoil100RN0 $0500 \mathrm{~m} 31000$ & 1.24723 & 0.00026 \\
\hline
\end{tabular} \begin{tabular}{|l|l|l|}
\hline hyOil ORNO $1000 \mathrm{~m} 05500$ & 0.63582 & 0.00025 \\
\hline
\end{tabular} \begin{tabular}{|l|l|l|}
\hline hyO1100RNO1000m10000 & 0.80659 & 0.00028 \\
\hline
\end{tabular} \begin{tabular}{|l|l|l|l|}
\hline hyoi 100 RNO $1000 \mathrm{~m} 14500$ & 0.91531 & 0.00028 \\
\hline
\end{tabular} \begin{tabular}{|l|l|l|l|}
\hline hyoil 00 RNO $1000 \mathrm{~m} 19000$ & 0.99376 & 0.00029 \\
\hline
\end{tabular} \begin{tabular}{|l|l|l|l|}
\hline hyOil OORNO1000m23500 & 1.05407 & 0.00028 \\
\hline
\end{tabular} \begin{tabular}{|l|l|l|l|}
\hline hyOilOORNO1000m28000 & 1.10364 & 0.00028 \\
\hline
\end{tabular} \begin{tabular}{|l|l|l|l|}
\hline hyOilOORNO $1000 \mathrm{~m} 32500$ & 1.14435 & 0.00030 \\
\hline
\end{tabular} \begin{tabular}{|l|l|l|l|}
\hline hyoil 00 RNO $1000 \mathrm{~m} 37000$ & 1.18004 & 0.00028 \\
\hline
\end{tabular} \begin{tabular}{|l|l|l|}
\hline hyoil OORNO1000m41500 & 1.21036 & 0.00029 \\
\hline
\end{tabular} \begin{tabular}{|l|l|l|}
\hline hyOilOORNO1000m46000 & 1.23640 & 0.00029 \\
\hline
\end{tabular} \begin{tabular}{|l|l|l|l|}
\hline hyoil 100 RNO2000m06000 & 0.57468 & 0.00023 \\
\hline
\end{tabular} \begin{tabular}{|l|l|l|l|}
\hline hyOil 100 RNO $2000 \mathrm{~m} 12000$ & 0.76366 & 0.00024 \\
\hline
\end{tabular} \begin{tabular}{|l|l|l|l|}
\hline hyoil 100 RN02000m18000 & 0.88169 & 0.00026 \\
\hline
\end{tabular} \begin{tabular}{|l|l|l|l|}
\hline hyoil 00 RNO $2000 \mathrm{~m} 24000$ & 0.96571 & 0.00028 \\
\hline
\end{tabular} \begin{tabular}{|l|l|l|}
\hline hyoil OORN02000m30000 & 1.03143 & 0.00028 \\
\hline
\end{tabular} \begin{tabular}{|l|l|l|}
\hline hyoil 100 RNO $2000 \mathrm{~m} 36000$ & 1.08466 & 0.00029 \\
\hline
\end{tabular} \begin{tabular}{|l|l|l|}
\hline hyoil OORNO $2000 \mathrm{~m} 42000$ & 1.12944 & 0.00029 \\
\hline
\end{tabular} \begin{tabular}{|l|l|l|l|}
\hline hyOil 100 RNO2000m48000 & 1.16720 & 0.00029 \\
\hline
\end{tabular} \begin{tabular}{|l|l|l|}
\hline hyOilOORNO $2000 \mathrm{m54000}$ & 1.20053 & 0.00027 \\
\hline
\end{tabular} \begin{tabular}{|l|l|l|l|}
\hline hYO1100RNO2000m60000 & 1.22943 & 0.00027 \\
\hline
\end{tabular} \begin{tabular}{|l|l|l|l|}
\hline hyoil 100 RN0 $3000 \mathrm{m06000}$ & 0.55437 & 0.00022 \\
\hline
\end{tabular} \begin{tabular}{|l|l|l|}
\hline hYOI10ORN03000m12000 & 0.73493 & 0.00024 \\
\hline
\end{tabular} \begin{tabular}{|l|l|l|l|}
\hline hyOil ONNO $3000 \mathrm{~m} 18000$ & 0.85130 & 0.00025 \\
\hline
\end{tabular} \begin{tabular}{|l|l|l|l|}
\hline hyoil 00 RNO $3000 \mathrm{~m} 24000$ & 0.93574 & 0.00027 \\
\hline
\end{tabular} \begin{tabular}{|l|l|l|l|}
\hline hyOil OORNO $3000 \mathrm{~m} 30000$ & 1.00245 & 0.00028 \\
\hline
\end{tabular} \begin{tabular}{|l|l|l|l|}
\hline hyOil OORNO $3000 \mathrm{~m} 36000$ & 1.05677 & 0.00027 \\
\hline
\end{tabular} \begin{tabular}{|l|l|l|l|}
\hline hyoil 100 RNO $3000 \mathrm{~m} 42000$ & 1.10263 & 0.00029 \\
\hline
\end{tabular} \begin{tabular}{|l|l|l|l|}
\hline hyOil O0RNO $3000 \mathrm{~m} 48000$ & 1.14137 & 0.00029 \\
\hline
\end{tabular} \begin{tabular}{|l|l|l|l|}
\hline hyoil 00RN03000m54000 & 1.17565 & 0.00029 \\
\hline
\end{tabular} \begin{tabular}{|l|l|l|l|}
\hline hyoi 1100 RNO $3000 \mathrm{~m} 60000$ & 1.20673 & 0.00031 \\
\hline
\end{tabular} \begin{tabular}{|l|l|l|}
\hline hyoil 00 RNO $5000 \mathrm{~m} 05000$ & 0.52859 & 0.00017 \\
\hline
\end{tabular} \begin{tabular}{|l|l|l|l|}
\hline hyOil OORNO5000m10000 & 0.69356 & 0.00020 \\
\hline
\end{tabular} \begin{tabular}{|l|l|l|}
\hline hyoil100RN0 $5000 \mathrm{~m} 15000$ & 0.80305 & 0.00021 \\
\hline
\end{tabular} \begin{tabular}{|l|l|l|}
\hline hyO1100RN05000m20000 & 0.88591 & 0.00024 \\
\hline
\end{tabular} \begin{tabular}{|l|l|l|l|}
\hline hyoil 100 RN0 $5000 \mathrm{~m} 25000$ & 0.95173 & 0.00024 \\
\hline
\end{tabular} \begin{tabular}{|l|l|l|l|}
\hline hyoil OORNO5000m30000 & 1.00642 & 0.00025 \\
\hline
\end{tabular} \begin{tabular}{|l|l|l|l|}
\hline hyO1100RNO5000m35000 & 1.05320 & 0.00025 \\
\hline
\end{tabular} \begin{tabular}{|l|l|l|}
\hline hyoil100RN05000m40000 & 1.09401 & 0.00027 \\
\hline
\end{tabular} \begin{tabular}{|l|l|l|}
\hline hyoil OORN0 $5000 \mathrm{~m} 45000$ & 1.12975 & 0.00026 \\
\hline
\end{tabular} \begin{tabular}{|l|l|l|}
\hline hyOil00RN05000m50000 & 1.16190 & 0.00026 \\
\hline
\end{tabular} \begin{tabular}{|l|l|l|l|}
\hline hyoil100RN10000m06500 & 0.69398 & 0.00015 \\
\hline
\end{tabular} \begin{tabular}{|l|l|l|}
\hline hyoil 00RN10000m09000 & 0.77411 & 0.00016 \\
\hline
\end{tabular} \begin{tabular}{|l|l|l|l|}
\hline hyoil 00RN10000m1 1500 & 0.83889 & 0.00018 \\
\hline
\end{tabular} \begin{tabular}{|l|l|l|l|}
\hline hyoil 00RN10 000m14000 & 0.89322 & 0.00017 \\
\hline
\end{tabular} \begin{tabular}{|l|l|l|l|}
\hline hyOil00RN10000m16500 & 0.93997 & 0.00020 \\
\hline
\end{tabular} \begin{tabular}{|l|l|l|l|}
\hline hyoil $100 \mathrm{RN} 10000 \mathrm{~m} 19000$ & 0.98146 & 0.00019 \\
\hline
\end{tabular} \begin{tabular}{|l|l|l|l|}
\hline hyoil OORN10000m21500 & 1.01847 & 0.00022 \\
\hline
\end{tabular} \begin{tabular}{|l|l|l|l|}
\hline hyoil 00RN1 $0000 \mathrm{~m} 24000$ & 1.05180 & 0.00021 \\
\hline
\end{tabular} \begin{tabular}{|l|l|l|l|}
\hline hyO $1100 R N 10000 \mathrm{~m} 26500$ & 1.08287 & 0.00020 \\
\hline
\end{tabular} \begin{tabular}{|l|l|l|}
\hline hyo1100RN1 $0000 \mathrm{~m} 29000$ & 1.11062 & 0.00020 \\
\hline
\end{tabular} \begin{tabular}{|l|l|l|l|}
\hline hyoil00RN15000m04500 & 0.72400 & 0.00014 \\
\hline
\end{tabular} \begin{tabular}{|l|l|l|}
\hline hyO1100RN15000m06000 & 0.79273 & 0.00014 \\
\hline
\end{tabular} \begin{tabular}{|l|l|l|}
\hline hYOIIO0RN15000m07500 & 0.84942 & 0.00015 \\
\hline
\end{tabular} \begin{tabular}{|l|l|l|}
\hline hyoi 100RN1 $5000 \mathrm{m09000}$ & 0.89819 & 0.00017 \\
\hline
\end{tabular} \begin{tabular}{|l|l|l|l|}
\hline hyoilooRN15000m10500 & 0.94046 & 0.00017 \\
\hline
\end{tabular} \begin{tabular}{|l|l|l|}
\hline hyoilo0RN15000m12000 & 0.97837 & 0.00017 \\
\hline
\end{tabular} \begin{tabular}{|l|l|l|}
\hline hyoil00RN15000m13500 & 1.01259 & 0.00018 \\
\hline
\end{tabular} \begin{tabular}{|l|l|l|}
\hline hyoilooRN15.000m15000 & 1.04446 & 0.00019 \\
\hline
\end{tabular} \begin{tabular}{|l|l|l|}
\hline hyo1100RN15000m16500 & 1.07332 & 0.00019 \\
\hline
\end{tabular} \begin{tabular}{|l|l|l|}
\hline hyoil00RN15000m18000 & 1.09985 & 0.00019 \\
\hline
\end{tabular} \begin{tabular}{|l|l|l|l|}
\hline hyoil100RN1 $19600 \mathrm{m0} 03000$ & 0.72461 & 0.00013 \\
\hline
\end{tabular} \begin{tabular}{|l|l|l|l|}
\hline hyoil 00 RN19600m04000 & 0.79103 & 0.00013 \\
\hline
\end{tabular} \begin{tabular}{|l|l|l|}
\hline hyoil $00 R N 19600 \mathrm{m0} 0000$ & 0.84628 & 0.00015 \\
\hline
\end{tabular} \begin{tabular}{|l|l|l|}
\hline hyoil00RN19600m06000 & 0.89334 & 0.00015 \\
\hline
\end{tabular} \begin{tabular}{|l|l|l|l|}
\hline hyoil 00 RN1 $19600 \mathrm{m0} 07000$ & 0.93453 & 0.00017 \\
\hline
\end{tabular} \begin{tabular}{|l|l|l|}
\hline hyoil 00 RN1 $9600 \mathrm{m0} 08000$ & 0.97164 & 0.00017 \\
\hline
\end{tabular} \begin{tabular}{|l|l|l|l|}
\hline hyoil100RN19600m09000 & 1.00508 & 0.00017 \\
\hline
\end{tabular} \begin{tabular}{|l|l|l|}
\hline hyoil100RN19600m10000 & 1.03579 & 0.00017 \\
\hline
\end{tabular} \begin{tabular}{|l|l|l|l|}
\hline hyoil100RN19600m11000 & 1.06416 & 0.00018 \\
\hline
\end{tabular} \begin{tabular}{|l|l|l|}
\hline hyo1100RN19600m12000 & 1.09014 & 0.00019 \\
\hline
\end{tabular} 